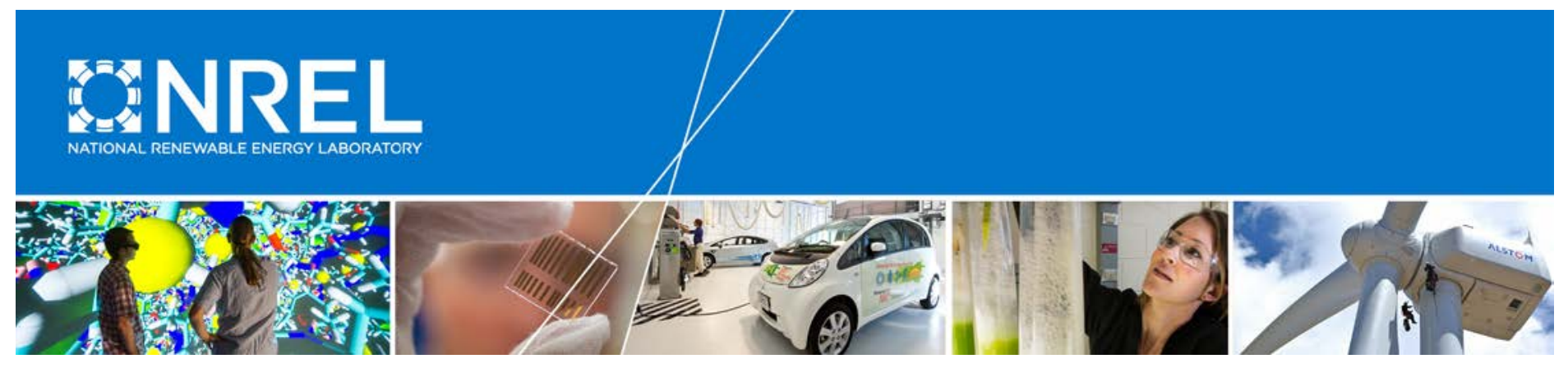

\title{
Utility-Scale Photovoltaic Deployment Scenarios of the Western United States: Implications for Solar Energy Zones in Nevada
}

Bethany Frew, Trieu Mai, Venkat Krishnan, and Scott Haase

National Renewable Energy Laboratory

NREL is a national laboratory of the U.S. Department of Energy Office of Energy Efficiency \& Renewable Energy Operated by the Alliance for Sustainable Energy, LLC

This report is available at no cost from the National Renewable Energy Laboratory (NREL) at www.nrel.gov/publications.

Technical Report

NREL/TP-6A20-67066

December 2016 


\section{Utility-Scale Photovoltaic Deployment Scenarios of the Western United States: Implications for Solar Energy Zones in Nevada}

Bethany Frew, Trieu Mai, Venkat Krishnan, and Scott Haase

National Renewable Energy Laboratory

Prepared under Task No. WFGU.1060

NREL is a national laboratory of the U.S. Department of Energy Office of Energy Efficiency \& Renewable Energy Operated by the Alliance for Sustainable Energy, LLC

This report is available at no cost from the National Renewable Energy Laboratory (NREL) at www.nrel.gov/publications.

National Renewable Energy Laboratory 15013 Denver West Parkway Golden, CO 80401

303-275-3000 • www.nrel.gov
Technical Report

NREL/TP-6A20-67066

December 2016

Contract No. DE-AC36-08G028308 


\section{NOTICE}

This report was prepared as an account of work sponsored by an agency of the United States government. Neither the United States government nor any agency thereof, nor any of their employees, makes any warranty, express or implied, or assumes any legal liability or responsibility for the accuracy, completeness, or usefulness of any information, apparatus, product, or process disclosed, or represents that its use would not infringe privately owned rights. Reference herein to any specific commercial product, process, or service by trade name, trademark, manufacturer, or otherwise does not necessarily constitute or imply its endorsement, recommendation, or favoring by the United States government or any agency thereof. The views and opinions of authors expressed herein do not necessarily state or reflect those of the United States government or any agency thereof.

This report is available at no cost from the National Renewable Energy Laboratory (NREL) at www.nrel.gov/publications.

Available electronically at SciTech Connect http:/www.osti.gov/scitech

Available for a processing fee to U.S. Department of Energy and its contractors, in paper, from:

U.S. Department of Energy

Office of Scientific and Technical Information

P.O. Box 62

Oak Ridge, TN 37831-0062

OSTI http://www.osti.gov

Phone: 865.576.8401

Fax: 865.576.5728

Email: reports@osti.gov

Available for sale to the public, in paper, from:

U.S. Department of Commerce

National Technical Information Service

5301 Shawnee Road

Alexandria, VA 22312

NTIS http://www.ntis.gov

Phone: 800.553 .6847 or 703.605 .6000

Fax: 703.605.6900

Email: orders@ntis.gov 


\section{Acknowledgments}

The authors wish to thank the U.S Bureau of Land Management (BLM) for providing funding support for this study. Specifically from BLM, Greg Helseth, Jayme Lopez, and John Kalish provided guidance and input on the framework for the analysis, overall project direction, and review of early versions of the paper. Also from BLM, Michael Hildner provided valuable review and comments on the final report. We also wish to thank David Hurlbut, Kelly Eurek, Daniel Steinberg, Robin Newmark, Dave Mooney, Mary Werner, Gian Porro, Scott Gossett, Barbara O'Neill, and Robert Margolis of the National Renewable Energy Laboratory (NREL); Steve Capanna and Paul Donohoo-Vallett of the U.S. Department of Energy Strategic Programs Office; and 11 anonymous external reviewers from environmental non-governmental organizations and the solar industry for their comments and input on the draft versions of this document. We also thank David Feldman and Pieter Gagnon of NREL for providing various forms of PV data for our analysis. We are grateful for the editorial support from Mary Lukkonen and Mike Meshek of NREL. Funding for this work was provided by the U.S. Bureau of Land Management through Interagency Agreement number L14PG00274. The opinions presented in this report are the authors' and do not reflect the view of the U.S Bureau of Land Management, the U.S. Department of Energy, or the U.S. government. Any and all errors are the sole responsibility of the authors. 


\section{List of Acronyms}

\begin{tabular}{ll} 
AEO & Annual Energy Outlook \\
ATB & Annual Technology Baseline \\
BLM & U.S. Bureau of Land Management \\
BNEF & Bloomberg New Energy Finance \\
CAISO & California Independent System Operator \\
CPP & Clean Power Plan \\
CSP & concentrating solar power \\
DOE & U.S. Department of Energy \\
dSolar & Distributed Solar Market Demand Model \\
EIA & Energy Information Administration \\
EIM & Energy Imbalance Market \\
EPA & U.S. Environmental Protection Agency \\
GTM & Greentech Media Research \\
ITC & investment tax credit \\
NERC & North American Electric Reliability Corporation \\
NEM & net energy metering \\
NREL & National Renewable Energy Laboratory \\
PV & photovoltaic \\
REC & renewable energy certificate \\
ReEDS & Regional Energy Deployment System \\
RPS & renewable portfolio standard \\
SEIA & Solar Energy Industries Association \\
SEZ & solar energy zone \\
TWh & terawatt-hour \\
UPV & utility-scale photovoltaic \\
WECC & Western Electricity Coordinating Council \\
& \\
& \\
\hline
\end{tabular}




\section{Executive Summary}

In this study, we use the National Renewable Energy Laboratory's (NREL's) Regional Energy Deployment System (ReEDS) capacity expansion model to estimate utility-scale photovoltaic (UPV) deployment trends from the present through 2030. The analysis seeks to inform the U.S. Bureau of Land Management's (BLM's) planning activities related to UPV development on federal lands in Nevada as part of the resource management plan revision for the Las Vegas and Pahrump Field Offices. These planning activities include assessing the demand for new or expanded additional Solar Energy Zones (SEZ), per the process outlined in BLM's Western Solar Plan process.

We focus on three spatial extents: (1) Nevada only, (2) the three-state area of Nevada, California, and Arizona to capture important UPV deployment tradeoffs between these areas, and (3) the 11 states in the western United States which we define as the "U.S. West"-including Arizona, California, Colorado, Idaho, Montana, Nevada, New Mexico, Oregon, Utah, Washington, and Wyoming - to understand the broader trends across the region. We project UPV growth under a range of future technology, market, and policy conditions. Altogether, we model nine scenarios using distinct assumptions for photovoltaic (PV) technology costs, natural gas prices, and regional policy and economic sensitivities. Key findings include:

- Renewables are estimated to make up the majority of new capacity additions in the U.S. West. Deployment of new capacity across the broader U.S. West region of 11 states is driven primarily by clean energy policies, including state renewable portfolio standards (RPSs) and the U.S. Environmental Protection Agency's Clean Power Plan. ${ }^{1}$ Total capacity in the region is in excess of the North American Electric Reliability Corporation (NERC) reference reserve margins. As a result, we find that new capacity resources are not needed to meet resource adequacy or electricity consumption growth in the near term in most regions but are instead deployed to meet policy requirements. Cumulative UPV capacity across the U.S. West grows from a baseline of about $7 \mathrm{GW}_{\mathrm{DC}}$ in 2014 to 11-17 $\mathrm{GW}_{\mathrm{DC}}$ in 2020 and $11-87 \mathrm{GW}_{\mathrm{DC}}$ in 2030 , depending on the scenario. The largest projected installed UPV capacity across the U.S. West is achieved when natural gas fuel prices are assumed to increase well above current prices and/or PV costs decrease rapidly.

- California offers the largest opportunity for new UPV deployment in the U.S. West through 2030. California's RPS target of $50 \%$ by 2030 is a key driver of renewable deployment, including UPV, within California and for renewable project development in neighboring states. In particular, UPV deployment is found to be sensitive to California RPS rules for out-of-state resources. The scenario results indicate that non-California UPV resources can provide high-quality UPV resource to meet California policy requirements should market conditions favor those resources and if transmission access is available. The relative project development cost in California, driven for example by higher permitting costs, compared to development costs in neighboring states is found to be an important component of those market conditions. Distributed PV deployment can

\footnotetext{
${ }^{1}$ The Clean Power Plan's mass-based state emission goals were used to simulate the details of a plausible carbon reduction policy, as seen at the time of this study. See Section 2.1 for an explanation of assumptions.
} 
also influence UPV deployment in California and the region as it impacts electricity sales and corresponding RPS demand for new renewable energy.

- Under the range of scenarios presented here, UPV development in Nevada is projected to reach $1.2 G W_{D C}$ of cumulative capacity by 2020 and $1.2-13.2 G W_{D C}$ by 2030, from a 2014 baseline of $0.6 G W_{D C}$. The corresponding land area required for this deployment is about 4,600-6,500 acres for new UPV capacity builds between 2015 and 2020 and 0-119,000 acres for new UPV capacity builds between 2021 and 2030. Cumulative UPV capacity of greater than $4 \mathrm{GW}_{\mathrm{DC}}$ by 2030 is achieved if (1) high natural gas fuel prices and/or low PV costs are realized or (2) the higher relative cost to develop renewable resources in California is further amplified, thus shifting renewable resource deployment to more economically-favorable adjacent states such as Nevada. Conversely, the results suggest that if the opposite conditions prevail, UPV growth in Nevada can essentially stagnate over the study period. Results indicate that multiple possibilities exist for market conditions, policy conditions, or both to be favorable for UPV deployment in Nevada, but the future presence and extent of these factors is highly uncertain. In other words, the sensitivity of UPV deployment in Nevada to policy and economic factors across these scenarios reveals a lack of a single UPV market outlook - and therefore potentially a SEZ expansion plan - that is robust against multiple variables, such as natural gas prices, UPV costs, policy implications, and regional dynamics.

- As a fraction of total annual generation, the UPV share in Nevada meets or exceeds those in at least one of the neighboring states of California and Arizona for most of the scenarios. While Nevada is projected to remain the smallest UPV market in the NevadaArizona-California area on an absolute basis, UPV growth is expected to be much more similar across these states in 2020 and 2030 when normalized by market size.

This scenario analysis captures important technology, resource, and policy tradeoffs on the deployment of UPV in Nevada and the broader U.S. West. We find a large range of UPV and total solar deployment possibilities in the U.S. West across our nine scenarios, but a comparison of our results with other published projections indicate that an even wider range is possible. Under the range of scenarios analyzed in this study, ReEDS projects a range of total PV (rooftop PV and UPV) cumulative capacity in the U.S. West of 20-33 $\mathrm{GW}_{\mathrm{DC}}$ in 2020 and $25-122 \mathrm{GW}_{\mathrm{DC}}$ in 2030, from a baseline of $12 \mathrm{GW}_{\mathrm{DC}}$ in 2014. Some projections report 2020 total PV cumulative capacity estimates as high as $51 \mathrm{GW}_{\mathrm{DC}}$, over $50 \%$ higher than the largest ReEDS scenario 2020 projection. However, other projections estimate lower PV deployment in the 2024-2030 period. In addition, while the ReEDS projections see delayed PV growth in the very near term compared to some of the other estimates, once growth does occur, the growth rates are similar to many of the other estimates, particularly among the more aggressive ReEDS scenarios.

The wide range of deployment estimates highlights significant uncertainties in all projections, including the possibility for much greater and more rapid UPV deployment than is estimated in our modeling. Sources of uncertainty could include PV cost assumptions, the treatment of current policy such as the California RPS, the reaction to anticipated cost and/or policy changes, the impact of emerging markets for UPV from non-traditional customers such as corporate and industrial entities, the treatment of environmental and siting considerations that could shift UPV development to different geographic locations, and the treatment of local decision-making 
factors or broader economic components that could add or change the value proposition for UPV development.

Another potential source for differences is the accounting of projects in the interconnection queue. ReEDS accounts for all existing sites and projects under construction as of April 2016 (ABB 2016), which include UPV capacity of $7.9 \mathrm{GW}_{\mathrm{DC}}$ in California, $1.2 \mathrm{GW}_{\mathrm{DC}}$ in Nevada and $1.3 \mathrm{GW}_{\mathrm{DC}}$ in Arizona. However, these data do not capture the full potential project queue, including proposed and permitted projects. For example, the BLM has approved solar energy projects in southern Nevada that are in various stages of pre-construction or construction, or which have completed construction. This includes three utility-scale solar energy projects ${ }^{2}$ in the Dry Lake SEZ that were approved in December 2014 and which would generate a total of 480 $\mathrm{MW}_{\mathrm{DC}}$. The BLM has 10 grandfather status applications for utility-scale solar energy projects in southern Nevada, of which four are currently being processed for environmental analysis by the BLM. While many of the applications for utility-scale solar energy projects will not result in actual UPV deployment, they are indicative of a high level of solar energy industry interest in southern Nevada.

While there are inherent methodological and data limitations in the development of any future projection, we use a self-consistent modeling framework and a range of scenarios to provide data estimates of UPV deployment in the U.S. West. Our range of scenario projections, in combination with estimates from many others, can be used to inform BLM planning activities.

\footnotetext{
${ }^{2}$ None of these three projects was under construction as of April 2016 and none was thus included in the ReEDS project queue. However, at the time of this report, one of these three projects has begun construction, while the other two are under negotiations regarding a power purchase agreement.
} 


\section{Table of Contents}

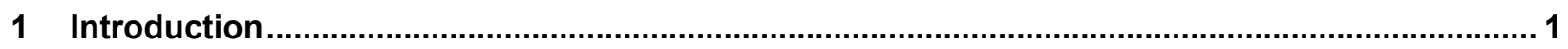

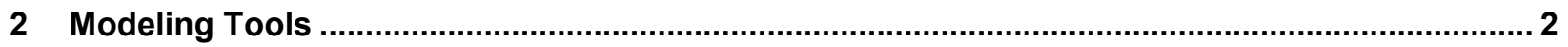

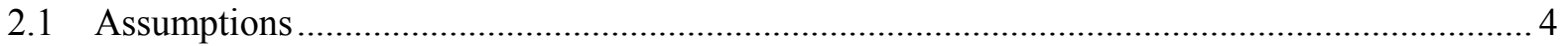

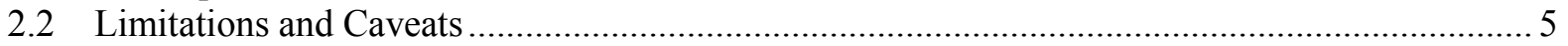

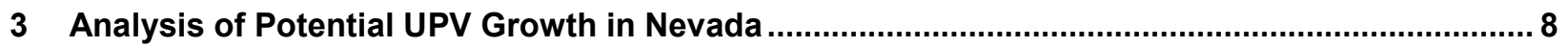

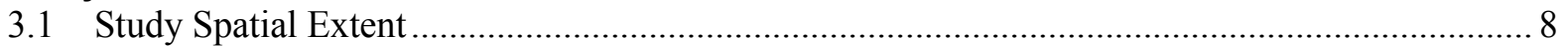

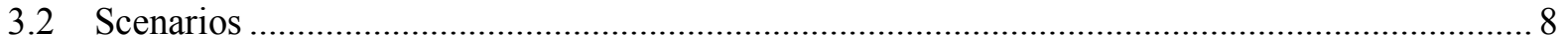

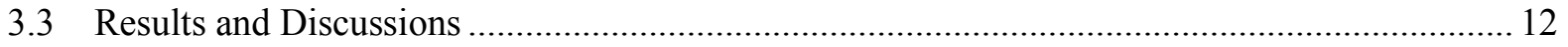

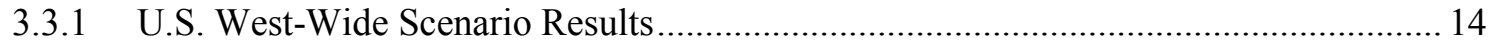

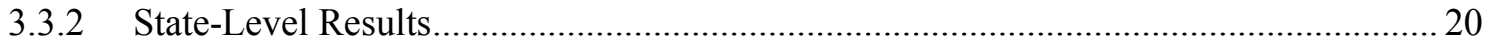

3.3.3 State-Level UPV Sensitivity to Broader Regional Dynamics ....................................... 25

3.3.4 Comparison with Other Published UPV Projections ................................................ 26

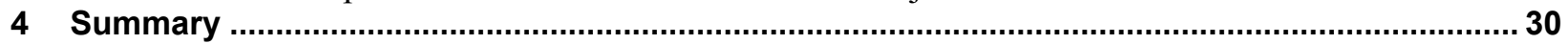

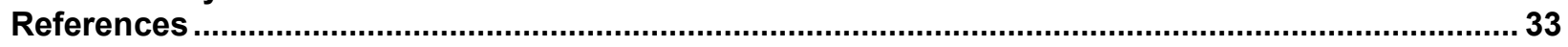

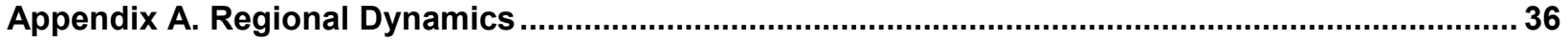

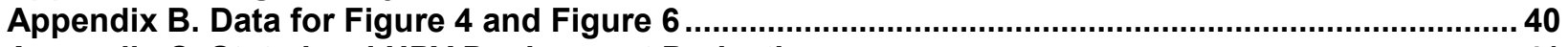

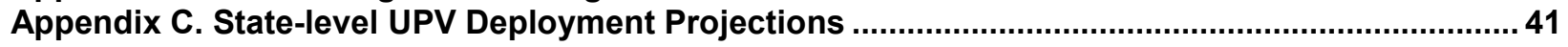




\section{List of Figures}

Figure 1. The 11 Western states comprising the U.S. West region (yellow) and the three-state area (red) . 8

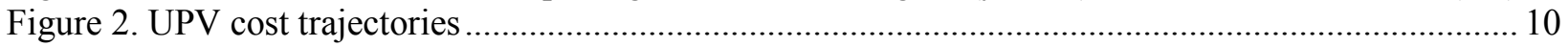

Figure 3. National-averaged natural gas price trajectories............................................................... 11

Figure 4. Central scenario U.S. West cumulative capacity ................................................................. 15

Figure 5. U.S. West cumulative capacity for Central and bounding scenarios ....................................... 15

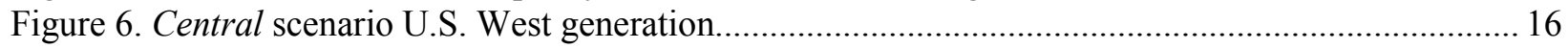

Figure 7. U.S. West annual generation for Central and bounding scenarios ........................................ 16

Figure 8. U.S. West cumulative capacity difference from Central scenario .......................................... 17

Figure 9. U.S. West annual generation difference from Central scenario .............................................. 18

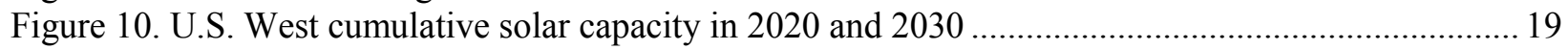

Figure 11. U.S. West solar generation as a percent of total generation in 2020 and 2030 .................... 19

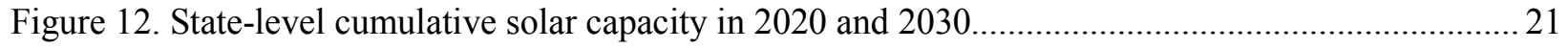

Figure 13. State-level solar generation as a percent of total generation in 2020 and $2030 \ldots \ldots \ldots \ldots \ldots \ldots \ldots \ldots . . . . . . .22$

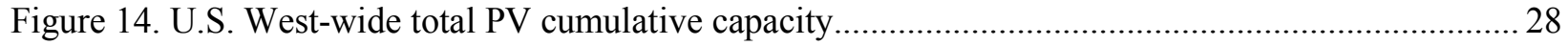

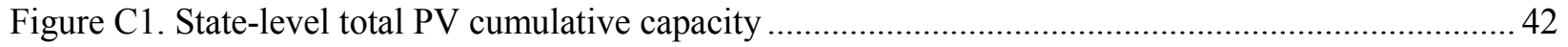

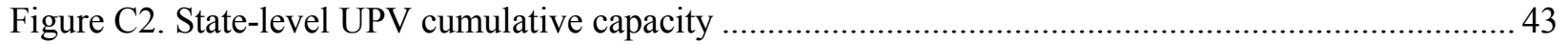

\section{List of Tables}

Table 1. Scenario Matrix: Natural Gas Price, PV Costs, and Additional Factors across Modeled Scenarios9

Table 2. Cumulative UPV Capacity $\left(\mathrm{GW}_{\mathrm{DC}}\right)$ for Central and U.S. West 2030 Bounding Scenarios ........ 14

Table 3. Statewide and Total UPV New Deployment per Time Period $\left(\mathrm{GW}_{\mathrm{DC}}\right)$....................................2 24

Table 4. Total Acres Required for Nevada UPV New Deployment per Time Period ..............................24

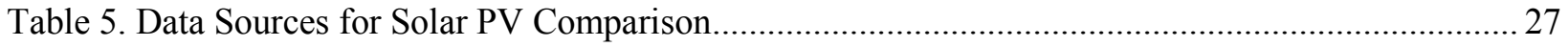

Table A1. State RPS Targets and Technology Set-Asides in ReEDS ................................................... 38

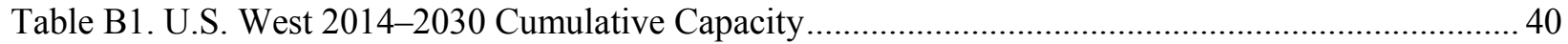

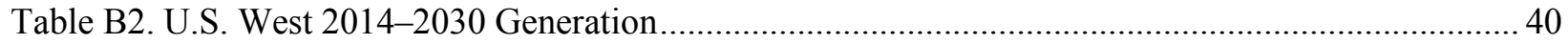




\section{Introduction}

The National Renewable Energy Laboratory (NREL) was commissioned by the U.S. Bureau of Land Management (BLM) Washington D.C office to assess the potential growth of utility-scale photovoltaic (UPV) deployment in Nevada. As part of the revision of the resource management plan for the Las Vegas and Pahrump Field Offices, the BLM is considering designating new or expanded solar energy zones (SEZs). ${ }^{3}$ The BLM's Western Solar Plan establishes a four step process for identifying new or expanded Solar SEZs, of which the first step is to "assess the demand for new or expanded SEZs" (BLM 2012, p. 168). The BLM will consider this report, as well as other solar energy market data, as part of the agency's demand assessment. ${ }^{4}$

To analyze the Nevada UPV market, we first place Nevada in the context of other Western states for a more comprehensive analysis. We focus on three spatial extents: (1) Nevada only, (2) the three-state area of Nevada, California, and Arizona to capture important UPV deployment tradeoffs between these areas, and (3) the 11 states in the western United States ("U.S. West") to understand the broader trends across these states, which include Arizona, California, Colorado, Idaho, Montana, Nevada, New Mexico, Oregon, Utah, Washington, and Wyoming. We develop a set of nine scenarios to explore a range of potential UPV deployment futures at these three spatial extents. Finally, we place our results in the context of other published projections to present a more comprehensive deployment outlook.

For this analysis, we use the National Renewable Energy Laboratory's (NREL's) Regional Energy Deployment System (ReEDS $)^{5}$ electric sector capacity expansion model, along with the Distributed Solar Market Demand Model (dSolar) (Sigrin et al. 2016; Cole et al. 2016a), to estimate electric sector supply-side PV—specifically UPV — deployment and generation trends through 2020 and 2030. This modeling effort captures the dynamic balances between growth in electricity consumption, plant retirement, competing generation options, and policies that will affect the regional demand for new UPV resources over time.

\footnotetext{
${ }^{3}$ A SEZ is an area well suited for utility-scale production of solar energy where BLM prioritizes solar energy and associated transmission infrastructure development (BLM 2012). BLM also designates variance areas outside of SEZs where solar development is open to application but requires developers to adhere to the variance process.

${ }^{4}$ The remaining SEZ steps, including the tasks of identifying and comparing potential SEZ locations, are outside the scope of this analysis and are left to the BLM.

${ }^{5}$ http://www.nrel.gov/analysis/reeds/
} 


\section{Modeling Tools}

The ReEDS model is an electricity system capacity expansion model that simulates the construction and operation of generation and transmission capacity across the continental United States from present day ${ }^{6}$ to 2050 . ReEDS calculates the competing costs of differing energy supply options and selects the most cost-effective solution. Model results are based on total system costs, which account for the type and location of fossil, nuclear, renewable, and storage resource development; the transmission infrastructure expansion requirements of those installations; and the generator dispatch and fuel needed to satisfy regional electricity consumption requirements and maintain grid system adequacy.

ReEDS represents the electric sector with high spatial resolution to enable comparative electricity sector cost evaluation based on local costs, regional pricing, and the relative value of geographically and temporally constrained renewable power sources. Within ReEDS, the continental United States is divided into 134 modeling regions, wherein electricity supply and consumption are balanced and planning reserves are enforced. ReEDS characterizes the quality, variability, uncertainty, and geographic resource constraints of renewable resources across different regions, and in some cases, sub-categories of resource technologies. Rooftop PV, UPV, geothermal, and biomass resources are modeled across the 134 modeling regions, while wind and CSP are divided into 356 total resource regions. Each of these renewable resources is further categorized into resource quality classes with corresponding resource supply curves. Both the 134 modeling regions and 356 resource regions follow state boundaries. In ReEDS, UPV represents any PV plant that is not installed behind the meter.

Long-distance transmission is represented as single-path connections between most adjacent or near-adjacent modeling regions, and ReEDS models both existing transmission lines as well as new transmission capacity on these inter-region lines. New transmission is further divided into prescribed and possible (if economic) builds through 2020, and endogenously chosen economic builds after 2020. Relevant to the focus region of this study, some limitations exist in the allowed California-Arizona-Nevada transmission corridors through $2020,{ }^{7}$ but ReEDS allows new interregion transmission line builds between all possible adjacent regions in this three-state area after 2020. Within each time slice, ReEDS captures the inter-region flow of each generator type, thereby accounting for the seasonal and daily changes in resource and transmission capacity availability. ReEDS also models the intra-region "spur line" transmission costs required to interconnect renewable capacity from their resource region to the transmission grid or load centers. However, both the inter-region transmission lines and intra-region spur line cost components are aggregated across each modeling region, precluding the ability of ReEDS to capture individual sites or spatially detailed transmission build outs.

\footnotetext{
${ }^{6}$ ReEDS includes all existing and under-construction projects as of April 2016 in the ABB Velocity Suite database (ABB 2016).

${ }^{7}$ However, key U.S. West transmission projects are included in ReEDS. For example, allowed DC transmission builds before 2020 include the Southwest Intertie and SunZia Southwest; allowed DC transmission builds include Zephyr and Southern Cross. The TransWest project, which is still in the proposed phase at the time of this study, is not included. A full list of allowed transmission builds in ReEDS can be found in Appendix G of the Wind Vision study (DOE 2015).
} 
For each two-year solution interval from 2010 to 2050, ReEDS dispatches all generation using 17 time slices to capture seasonal and diurnal electricity consumption and renewable generation profiles. ReEDS explicitly and dynamically estimates and considers the need for new interregional transmission (limited through 2020), increases in operating reserve requirements, and changing contributions to planning reserves that may be driven by increases in renewable generation. For this purpose, ReEDS includes statistical parameters, such as capacity value for planning reserve requirements, forecast error operating reserve requirements, and estimated curtailments. More detailed information on the temporal resolution of generation dispatch representation and statistical operational parameter estimations in ReEDS for each solve year can be found in the documentation by Short et al. (2011) and ReEDS documentation (Eurek et al. 2016).

The ReEDS model also considers technology, resource, and policy considerations including state renewable portfolio standards (RPS) and the U.S. Environmental Protection Agency's (EPA's) Clean Power Plan (CPP). ${ }^{8}$ The primary outputs from ReEDS include the amount, type, year, and location of generator capacity; annual generation from each technology; storage capacity expansion; and transmission capacity expansion needed to satisfy regional electricity consumption requirements and maintain grid system adequacy. The generation and storage technologies modeled in ReEDS include coal-fired (pulverized coal with and without scrubbers, biomass cofiring, integrated gasification combined cycle with and without carbon capture and storage), natural-gas-fired (combined cycle and combustion turbines), oil and gas steam, nuclear, wind (land-based and offshore), biopower, geothermal, hydropower, UPV, concentrating solar power (CSP) with and without thermal energy storage, pumped-hydropower storage, compressed-air energy storage (CAES), and utility-scale batteries.

The 2015 Standard Scenarios Annual Report (Sullivan et al. 2015), 2016 Standard Scenarios Report (Cole et al. 2016b), ReEDS documentation (Short et al. 2011), and ReEDS documentation (Eurek et al. 2016) provide more detailed descriptions of the model structure and equations. Among many publications using ReEDS, a few of note include the SunShot Vision Study (DOE 2012), the Renewable Electricity Futures study (Mai et al. 2012), and the Wind Vision study (DOE 2015).

With a system-wide central-planner perspective, ReEDS is not designed to evaluate distributed technology adoption decisions such as rooftop solar photovoltaic (PV) adoption. For this purpose, ReEDS is supported by the dSolar model (Sigrin et al.2016; Cole et al. 2016a) ${ }^{9}$ that produces scenarios of market uptake of distributed solar PV considering the electricity consumption projections for various industrial, residential, and commercial customers; resource and generation capacity potentials in their respective building rooftops; regional electricity rate structures; and estimated cost savings. This linking of a transmission-level capacity expansion model (ReEDS) with a rooftop PV adoption model (dSolar) enables us to capture the interaction of rooftop PV deployment with the broader bulk power system. In this analysis, we use exogenous rooftop PV deployment projections created in previously linked dSolar-ReEDS model runs with case-specific cost projections. In the scenarios presented in this report, ReEDS solves

\footnotetext{
${ }^{8} \mathrm{http}: / /$ www.epa.gov/cleanpowerplan

${ }^{9}$ For residential PV, dSolar considers adoption of host-owned and third-party-owned systems. dSolar is an updated version of the NREL SolarDS model (Denholm et al. 2009; Drury et al. 2013).
} 
for the remaining capacity and generation needs of the system after accounting for the fixed rooftop PV deployment. In this way, we capture the impact of rooftop PV under various growth assumptions on UPV and other technologies, which then compete for the remaining capacity and energy needs. The dSolar model incorporates the retail electricity tariffs available to potential distributed generation customers, including the formulation of net energy metering (NEM) in Nevada that was implemented in December 2015 and modified in February 2016; we discuss the recent NEM changes in Nevada in the following section. Under this form of NEM, dSolar projects little growth in the rooftop PV market.

\subsection{Assumptions}

We use the ReEDS model 2016 version with minor variants. ${ }^{10}$ This 2016 version of the model and associated inputs are described in detail by Cole et al. (2016b). Key data assumptions are primarily based on the Energy Information Administration's (EIA's) Annual Energy Outlook (AEO) 2016 report (EIA 2016), NREL's 2016 Standard Scenarios Report (Cole et al. 2016b), and ReEDS documentation (Eurek et al. 2016). Key assumptions are highlighted in this section.

All technology cost and performance input assumptions for ReEDS are from NREL's 2016 Annual Technology Baseline (ATB) (NREL 2016), which contains current and future cost and performance projections for electricity generating units for the U.S. electricity sector. For conventional technologies, these costs are based on the AEO 2016 Reference Case (EIA 2016). Annual electric consumption and fuel price supply curves are exogenously specified based on AEO scenarios (EIA 2016). We use the same electricity consumption profiles for each of our scenarios. ReEDS accounts for economic and prescribed generator retirements (Cole et al. 2016b) and applies standardized financing assumptions to evaluate investment decisions on a 20 year net present value basis (Mai et al. 2015). Because ReEDS focuses on the utility-scale bulk power system and therefore does not represent customer adoption, we do not explicitly include growth or shifting of electricity consumption from electric vehicle charging, efficiency, demand response, except for what is implicitly embedded within the AEO scenarios.

Policies modeled in ReEDS include state RPSs (including technology set-asides and the California RPS target of $50 \%$ by 2030), state and regional carbon emissions policies, ${ }^{11}$ federal tax credit extensions for various renewable energy technologies (including those outlined in the Consolidated Appropriations Act of 2016), and the CPP. It is assumed that all states achieve compliance with the CPP using a mass-based approach with the new source complement targets. With respect to state RPS rules, ReEDS allows eligible states to purchase out-of-state renewable energy certificates (RECs) ${ }^{12}$ as a mechanism for compliance with the RPS targets; however, ReEDS limits inter-state REC trading between certain states to observed historical percentages (Holt 2014; Heeter et al. 2015). More details on the REC trading framework within ReEDS are provided in Appendix A. In addition, ReEDS does not account for the impact from California's energy efficiency targets as part of its 50\% RPS policy. For each state, ReEDS defines the

\footnotetext{
${ }^{10}$ Custom modifications were made to allow separate treatment of RECs for California, and to enable a special case where California can receive up to $100 \%$ of its RPS requirements from out-of-state eligible resources in the form of bundled and/or unbundled RECs. See Appendix A for details on RPS representation in ReEDS.

${ }^{11}$ Carbon caps set forth by California's Assembly Bill 32 and the Regional Greenhouse Gas Initiative are modeled.

${ }^{12}$ RECs represent the attributes of renewable generation and can be sold separately ("unbundled") or together ("bundled") with the underlying electricity. One REC equals one megawatt-hour of qualifying renewable energy. For more information on REC claims see: http://www.nrel.gov/docs/fy15osti/64558.pdf
} 
eligible set of resources that may contribute to that state's RPS target; in California, the contribution from rooftop PV does not count towards RPS compliance, per California's RPS rules.

For the CPP, we assume that all states implement a mass-based compliance approach with new source complement targets for each state, and we allow for full allowance trading between the states. ${ }^{13}$ We recognize that significant uncertainties exist in future state plans for CPP compliance. The assumed compliance approach is intended to capture the bulk impacts of the $\mathrm{CPP}$ as the policy existed at the time of this study, but it is important to note that alternative compliance strategies could impact outcomes. We include a representation of the Clean Energy Incentive Program of the CPP and a simplified representation of allowance banking. ${ }^{14}$ Overall, our CPP representation only reflects a simplifying choice and we do not evaluate how results might change with different compliance scenarios. ${ }^{15}$

Additionally, state-level NEM policies are modeled through the linkage with dSolar. As mentioned earlier, inputs for rooftop PV capacity are provided to ReEDS exogenously from the dSolar model. For Nevada, we use rooftop PV deployment trajectories created in an updated version of dSolar for Nevada (Gagnon et al. 2016) that includes an updated representation of the tariffs available to distributed energy customers to reflect the NEM policy changes implemented by the Public Utility Commission of Nevada in December 2015 and modified in February 2016. ${ }^{16}$ If unchanged, these proposed NEM modifications are predicted by some to make the Nevada market more favorable for UPV (BNEF 2016a). Installed rooftop PV and UPV performance is assumed to degrade by $0.5 \%$ /year, and the dSolar and ReEDS models assume that these systems are maintained over time, as reflected by an annualized fixed O\&M cost.

\subsection{Limitations and Caveats}

ReEDS scenarios are not forecasts, but they provide a framework for exploring the potential impacts of technological development, policy changes, and economic conditions on the evolution of the electricity system. A detailed discussion on ReEDS caveats is found in Mai et al. (2016); however, some of the key limitations are itemized here:

- System-wide optimization-ReEDS takes a system-wide least-cost perspective that does not necessarily reflect the perspectives of or revenue impacts for individual decision makers, including specific investors, regional market participants, or other industry participants. The model does not account for corporate or consumer choice of renewable power ${ }^{17}$ such as UPV; nor does it model contractual obligations, non-economic decisions,

\footnotetext{
${ }^{13}$ It is assumed that allowances are auctioned and that revenues from auctioned are recycled in lump sum to consumers.

${ }^{14}$ The Clean Energy Incentive Program offers incentives for early (pre-compliance period) investment in renewable generation capacity, as well as low-income energy.

${ }^{15}$ Forthcoming research using ReEDS will examine a broad range of sensitivities with respect to CPP compliance options (Steinberg et al. forthcoming). In addition, further details on the representation of the CPP in ReEDS will be provided in a documentation report (Eurek et al. 2016).

${ }^{16}$ See Gagnon et al. (2016) for more details on the modeling assumptions used to create this Nevada rooftop deployment trajectory.

17 As an example, Community Choice Aggregation in California is driven by local interests in procurement of renewable energy.
} 
or voluntary markets. The model also does not fully represent the broader U.S. or global energy economy, including competing uses of resources across sectors (e.g., natural gas). In addition, like other optimization models, ReEDS finds the absolute least-cost solution; this does not reflect real distributions and uncertainties in the parameters, and it results in a tendency to avoid "over-compliance" of policy (e.g., RPS or CPP), energy, or capacity demands. However, the heterogeneity resulting from the high spatial resolution of ReEDS does mitigate this to some degree. To capture the entire system, ReEDS necessarily adopts a reduced form representation of generation dispatch, while real-world electricity markets clearing processes and system operations take place chronologically at hourly or sub-hourly time intervals.

- Project pipeline - The model incorporates data of existing or under-construction generation projects as of April 2016 in the ABB Velocity Suite database (ABB 2016), but these data do not include all projects in the queue. For example, UPV projects with a "Permitted" status as of April 2016 include additional UPV capacity of $2.7 \mathrm{GW}_{\mathrm{DC}}$ in California, 0.6 $\mathrm{GW}_{\mathrm{DC}}$ in Nevada, and $0.3 \mathrm{GW}_{\mathrm{DC}}$ in Arizona. "Proposed" projects further represent UPV capacity of $3.5 \mathrm{GW}_{\mathrm{DC}}$ in California, $0.4 \mathrm{GW}_{\mathrm{DC}}$ in Nevada, and $1.8 \mathrm{GW}_{\mathrm{DC}}$ in Arizona. These "Permitted" and "Proposed" projects are not prescribed in ReEDS.

- Foresight and behavior-Except for limited foresight of future natural gas prices, the ReEDS model makes decision without foresight of future power system conditions (e.g., policies, capacity retirements, and growth of electricity consumption). For example, anticipated tax credit expirations have historically led to acceleration of project development. A similar effect may be seen in response to CPP compliance timelines. The lack of foresight also impacts the timing and coordination of new generation and transmission builds. ReEDS chooses and reports these components in their online operation year, which assumes that the permitting and construction phases were initiated appropriately in advance and that the development timing between new generation and any new transmission capacity on which they rely have been properly coordinated. By not including foresight of policy changes and the associated behavior of specific plant developers, ReEDS tends to meet but not over-comply with any electric system or policy requirements.

- Manufacturing, supply chain, and siting - The model does not fully capture noneconomic factors or constraints in the supply chain or manufacturing processes. Potential bottlenecks or delays caused in project development stages for new generation or transmission would not be fully reflected in the results. ReEDS also does not explicitly model siting and permitting processes, nor does it account for environmental factors and impacts within potential development areas. Furthermore, the impacts of SEZ designations or similar land management practices for project permitting are not explicitly modeled or considered. One example of such activities to balance environmental considerations and the development of renewable resources on federal lands is the Desert Renewable Energy and Conservation Plan (DRECP). 
- Financing interactions - Financial parameters used in ReEDS and dSolar reflect longterm historical averages as opposed to current or near-term market conditions. In addition, the models do not fully capture financing interactions with tax credits (Bolinger 2014); however, we do model changes in capital structure for utility-scale wind and solar caused by changes in tax credits (Mai et al. 2015). Other interactions with tax equity investments are not reflected in the analysis.

- Technology learning-Future technology improvements are considered exogenously based on the assumptions in Section 2.1. 


\section{Analysis of Potential UPV Growth in Nevada}

\subsection{Study Spatial Extent}

ReEDS models the electricity sector across the full contiguous United States (Figure 1) but makes all decisions at the ReEDS modeling-region-level. For the purposes of this report, we aggregate those regional results to the state-level, where we then focus on (1) the aggregate of the states in the U.S. West (Figure 1, yellow), (2) the three-state area of California, Nevada, and Arizona (Figure 1, red), and (3) Nevada alone.

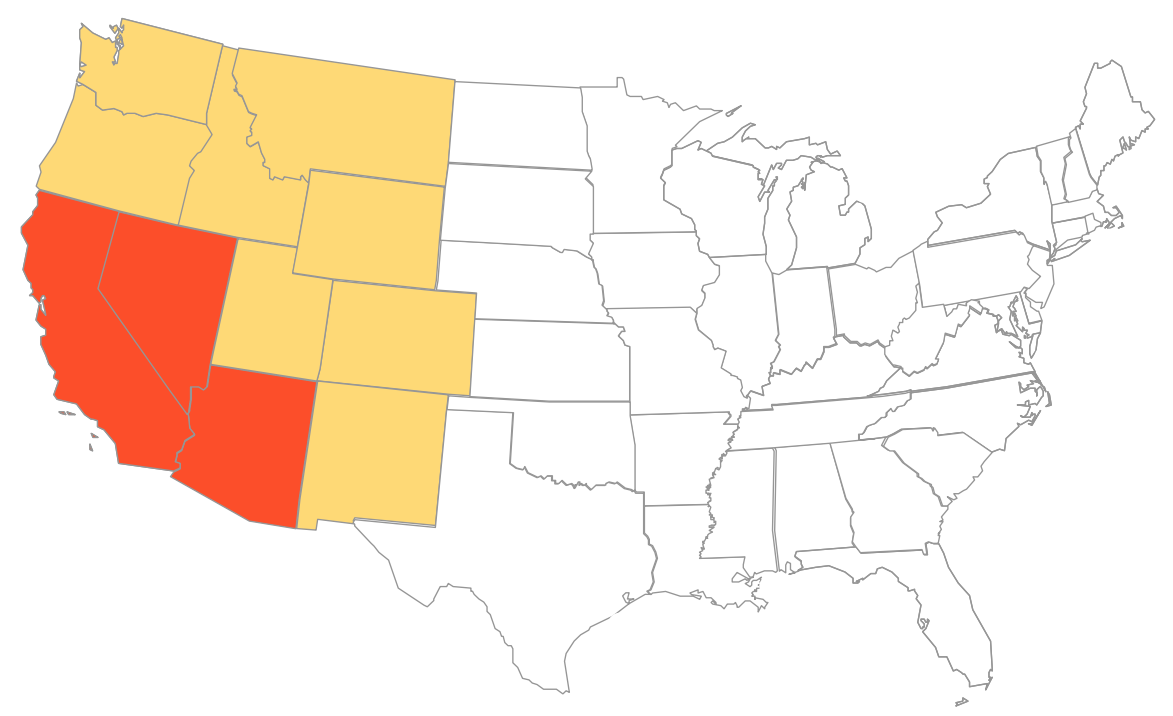

Figure 1. The 11 Western states comprising the U.S. West region (yellow) and the three-state area (red)

\subsection{Scenarios}

We investigate UPV deployment and generation trends under nine scenarios (Table 1). The Central scenario includes current policies (see Section 2.1) and central estimates of future technology cost, fuel price, and rooftop PV growth. In addition, eight sensitivity scenarios were evaluated to capture a range of UPV deployment possibilities based on market conditions that differ from the Central scenario assumptions. These sensitivities focus on the individual and combined impacts from natural gas price and PV costs assumptions, as well as scenarios to consider the impact of no new rooftop PV deployment after 2016, larger relative costs for developing renewable resources in California, and unlimited REC trading into California.

We run ReEDS nationwide for each scenario, with individual region-level inputs for each sensitivity parameter within this suite of scenarios. However, we present aggregated results for only the modeling regions in the U.S. West and the individual states of Nevada, California, and Arizona. None of the scenarios presented are intended to be predictions; rather, ReEDS and dSolar provide self-consistent frameworks to evaluate the potential impacts of different technology, market, and policy requirements on future PV deployment. 
Table 1. Scenario Matrix: Natural Gas Price, PV Costs, and Additional Factors across Modeled Scenarios

\begin{tabular}{|c|c|c|c|c|}
\hline & Scenario Names & $\begin{array}{l}\text { Natural Gas } \\
\text { Fuel Prices }\end{array}$ & $\begin{array}{l}\text { PV (UPV } \\
\text { and } \\
\text { Rooftop } \\
\text { PV) Costs }\end{array}$ & $\begin{array}{l}\text { Notes } \\
\text { (see Section } 3.2 \text { for details) }\end{array}$ \\
\hline & Central & Mid Price & Mid Cost & $\begin{array}{l}\text { ATB } 2016 \text { Mid case costs; Gagnon et } \\
\text { al. (2016) for NV rooftop PV } \\
\text { deployment; AEO } 2016 \text { Reference } \\
\text { scenario fuel prices and electricity } \\
\text { consumption values; default ReEDS } \\
\text { REC trading }\end{array}$ \\
\hline \multirow{2}{*}{$\begin{array}{l}\text { PV cost } \\
\text { sensitivity }\end{array}$} & Low PV Cost & Mid Price & Low Cost & ATB 2016 Low case PV cost \\
\hline & High PV Cost & Mid Price & High Cost & ATB 2016 High case PV cost \\
\hline \multirow{2}{*}{$\begin{array}{l}\text { Natural gas } \\
\text { fuel price } \\
\text { sensitivity }\end{array}$} & High NGas Price & High Price & Mid Cost & $\begin{array}{l}\text { AEO } 2016 \text { Low Oil and Gas } \\
\text { Resource scenario fuel prices }\end{array}$ \\
\hline & Low NGas Price & Low Price & Mid Cost & $\begin{array}{l}\text { AEO } 2016 \text { High Oil and Gas } \\
\text { Resource scenario fuel prices }\end{array}$ \\
\hline $\begin{array}{l}\text { Favorable PV } \\
\text { combination }\end{array}$ & $\begin{array}{l}\text { High PV } \\
\text { Deployment }\end{array}$ & High Price & Low Cost & \\
\hline $\begin{array}{l}\text { Unfavorable } \\
\text { rooftop PV } \\
\text { future }\end{array}$ & $\begin{array}{l}\text { No New Rooftop } \\
\text { PV }\end{array}$ & Mid Price & Mid Cost & $\begin{array}{l}\text { No new rooftop PV deployment } \\
\text { after } 2016\end{array}$ \\
\hline $\begin{array}{l}\text { Higher cost to } \\
\text { permit in CA }\end{array}$ & $\begin{array}{l}\text { Higher CA RE } \\
\text { Cost }\end{array}$ & Mid Price & Mid Cost & $\begin{array}{l}2 x \text { capital cost multiplier for all } \\
\text { renewable technologies in southern } \\
\text { CA; } 1.5 x \text { multiplier for all other CA } \\
\text { modeling regions }\end{array}$ \\
\hline $\begin{array}{l}\text { CA REC } \\
\text { compliance }\end{array}$ & $\begin{array}{l}\text { No CA REC } \\
\text { Limits }\end{array}$ & Mid Price & Mid Cost & $\begin{array}{l}\text { Allow unlimited bundled and } \\
\text { unbundled RECs from all WECC } \\
\text { states to contribute to CA's RPS }\end{array}$ \\
\hline
\end{tabular}

A large portion of the sensitivity scenarios are designed to examine the impact of natural gas, UPV, and rooftop PV cost assumptions. High natural gas prices make renewable technologies, such as UPV, more economically favorable, which tends to shift generation from natural gas units to those renewable technologies or would increase dispatch of non-natural gas thermal generators.

Among the natural gas fuel price and PV cost tradeoff scenarios, High PV Deployment is the most favorable for PV deployment, with the sensitivity levers aligned in a favorable direction for PV and unfavorable direction for natural gas. Conversely, High PV Cost is the least favorable among these scenarios for PV deployment, with the sensitivity levers aligned in an unfavorable direction for PV and neutral position for natural gas. The remaining sensitivities among these 
natural gas fuel price and PV cost tradeoff scenarios are intended to provide intermediate PV growth projections.

The UPV cost sensitivities are direct inputs to the ReEDS model, while the rooftop PV cost sensitivities are reflected through deployment trajectories that come as exogenous inputs to ReEDS from the dSolar model. The UPV "Mid Cost" trajectory corresponds to the ATB 2016 Mid case (NREL 2016). The UPV "Low Cost" and "High Cost" trajectories similarly correspond to the ATB Low and High cases, respectively. The ATB 2016 Mid and Low cases are developed based on aggregate literature projections (NREL 2016), whereas the High case simply keeps estimated 2016 costs constant for all future years. Figure 2 shows the three UPV cost trajectories, which correspond to those listed in Table 1. The UPV costs in Figure 2 represent the nation-wide overnight capital costs. ReEDS applies region-specific cost multipliers to these capital costs to account for regional differences in construction costs, interest during construction, and other financing costs (see Mai et al. 2015 and Beamon and Leff 2013); additional grid interconnection costs are included separately.

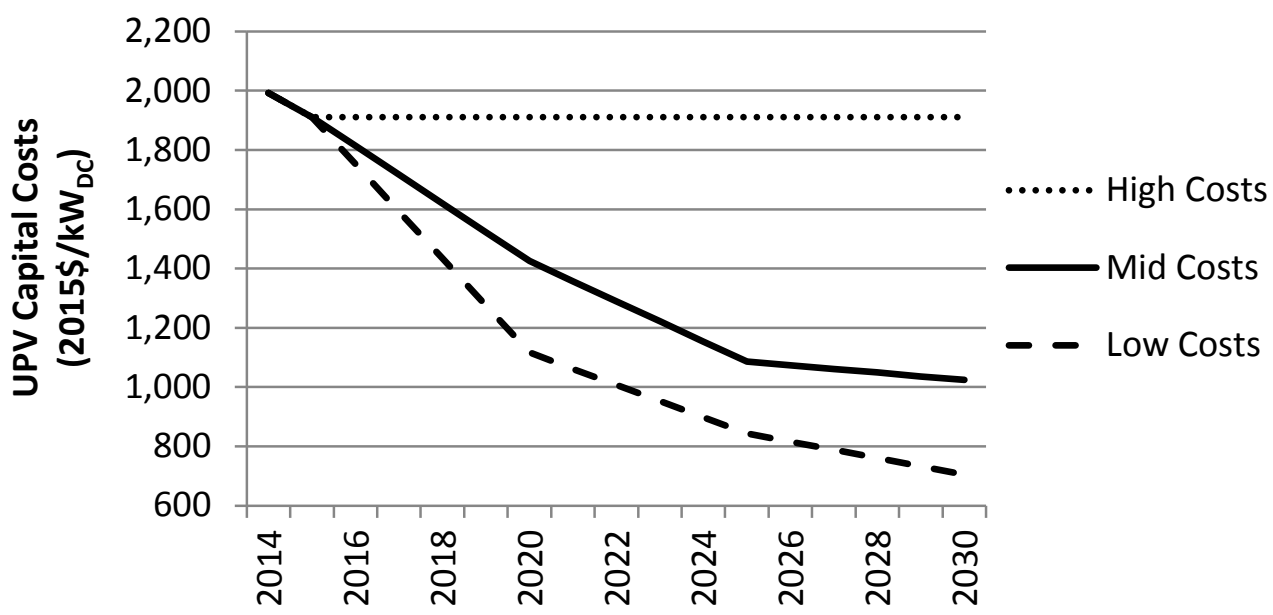

Figure 2. UPV cost trajectories

Our rooftop PV "Low Cost," "Mid Cost," and "High Cost" input deployment trajectories were produced by the dSolar model for the ReEDS 2016 version (Cole et al. 2016b) using the 2016 ATB Low, Mid, and High distributed residential PV cost trajectories (NREL 2016), respectively. However, for our "Low Cost" and "Mid Cost" Nevada rooftop PV deployment trajectories, we use a rooftop PV deployment projection from a more detailed Nevada dSolar simulation (Gagnon et al. 2016), ${ }^{18}$ which reflects recent NEM rule changes in Nevada and estimates much flatter rooftop PV deployment through 2030. For the "High Cost" Nevada case, we use the default ReEDS 2016 version dSolar rooftop PV deployment trajectory, as this projection has even lower deployment levels than those from Gagnon et al. (2016). The resulting "Mid Cost" rooftop PV deployment trajectories in aggregate across the U.S. West reach about $16 \mathrm{GW}_{\mathrm{DC}}$ of cumulative rooftop capacity in 2020 and just over $30 \mathrm{GW}_{\text {DC }}$ in 2030. In Nevada, the "Mid Cost" rooftop PV deployment trajectory reaches about $0.24 \mathrm{GW}_{\mathrm{DC}}$ of cumulative rooftop capacity in

\footnotetext{
${ }^{18}$ We used the "Enacted Tariffs, Mid PV Prices" scenario Nevada-wide rooftop PV capacity results distributed to the ReEDS modeling regions by their 2012 population weight. For historic years, cumulative capacity was set to actual installed cumulative rooftop capacity in Nevada (GTM 2016a).
} 
2020 and about $0.29 \mathrm{GW}_{\mathrm{DC}}$ in 2030. CSP technology cost inputs are also taken from the 2016 ATB (NREL 2016). For scenarios using the Mid, High, and Low ATB cost cases for UPV, CSP technology cost inputs assume the corresponding Mid, High, and Low ATB cost cases.

To address the uncertainty of future natural gas prices, we model High NGas Price and Low NGas Price scenarios with higher and lower natural gas prices, respectively, based on scenarios developed by the EIA. ${ }^{19}$ The national-averaged reference, high natural gas prices, and low natural gas prices are based on "AEO 2016 Reference," "AEO 2016 Low Oil and Gas Resource," and "AEO 2016 High Oil and Gas Resource" scenarios (EIA 2016), respectively, and are shown in Figure 3.

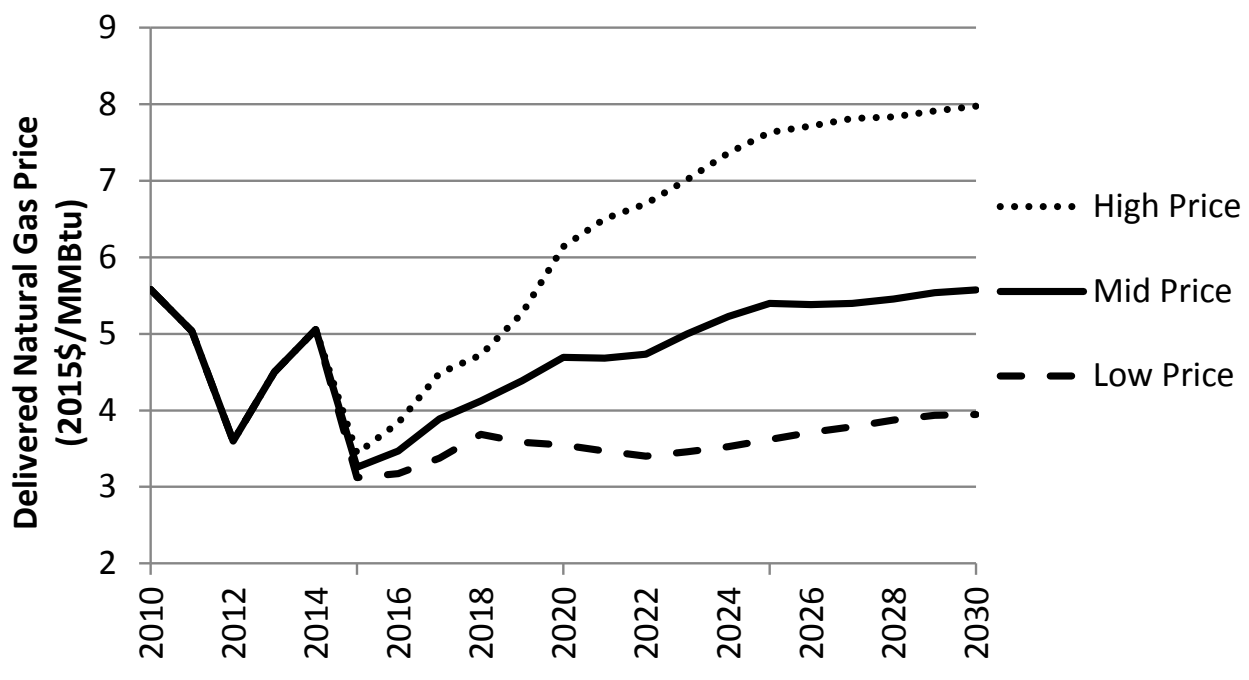

Figure 3. National-averaged natural gas price trajectories

In addition to the natural gas fuel price and PV cost tradeoff scenarios, we investigate three scenarios that capture broader market and/or policy impacts. These scenarios are designed to examine more extreme futures where external factors, whose dynamics cannot be directly modeled within ReEDS, could significantly shift market conditions for UPV and other renewable resources. We model a No New Rooftop $P V$ scenario, which reflects a future with no new rooftop PV deployment in any modeling region after 2016. While likely unrealistic, this scenario is designed as a bounding case reflecting futures where rate structures are severely unfavorable to rooftop PV owners, NEM is eliminated, or other distributed PV policy measures that disincentive rooftop PV deployment are implemented. Our Higher CA RE Cost scenario is designed to capture larger relative costs for developing renewable resources in California. The last scenario, No CA REC Limits, investigates the impact of unlimited REC trading into California.

The Higher CA RE Cost scenario applies higher capital cost multipliers to certain renewable capacity deployment in California as proxies for potential additional permitting costs in the state. In particular, ReEDS includes four modeling regions in California, one of which covers a large section of the sensitive desert area in Southern California. For this region, we apply a 2x capital

\footnotetext{
${ }^{19}$ ReEDS models regional and national natural gas supply curves to represent "inverse elasticities" or price responses to power sector consumption (Cole et al.2016c).
} 
cost multiplier to all PV, CSP, wind, and geothermal resource development. For all other ReEDS modeling regions in California, we apply a $1.5 x$ multiplier. These capital cost multipliers are in addition to the default ReEDS regional capital cost multipliers, which are based on values estimated by the Science Applications International Corporation for use in electric sector capacity expansion modeling (Beamon and Leff 2013), thereby further amplifying the relatively higher renewable resource cost within California and providing an incentive to shift development to the lower cost Nevada and/or Arizona regions. ${ }^{20}$ Actual costs of permitting and siting are difficult to estimate and generalize, especially for uncertain future development costs.

All scenarios include California's 50\% RPS by 2030 target. As per the "bucket" rules in California's RPS policy, ${ }^{21}$ California can import out-of-state RECs both in the form of bundled as well as unbundled RECs. While there is no specific limit on the net bundled RECs imported (based on Buckets 1 and 2), there is a limit on the net unbundled RECs imported (based on Bucket 3 limit). We model limits on net unbundled REC imports into California of $10 \%$ of its RPS requirement from 2017 onwards. ReEDS captures all of these out-of-state REC import constraints for California (see Appendix A for more details). However, it remains unclear how these REC trading rules for California might change under the 50\% RPS by 2030 policy and how they might change due to future market expansion activities in the U.S. West.

The No CA REC Limits sensitivity scenario allows California to utilize $100 \%$ of all eligible renewable resources across all U.S. West states, ignoring any bundling requirements, to comply with its RPS policy. This treatment is limited by the temporal and spatial resolution and transmission representation within ReEDS (see Section 2). This scenario serves as a proxy for the impact of possible greater regional coordination across the U.S. West, as reflected by multiple proposed and/or planned transmission expansion projects to physically connect California to the broader U.S. West (e.g., TransWest), as well as the growth of institutional cooperation (e.g., Energy Imbalance Market (EIM)). In addition, we acknowledge that Valley Electric Association in Nevada, which is part of the CAISO system and runs along the southwestern edge of Nevada, is included within ReEDS' northern Nevada modeling region in all of our scenarios due to the inherent regional boundary divisions within ReEDS. Furthermore, possible expansion of the CAISO beyond state boundaries could further complicate RE eligibility for RPS requirements. How the physical and institutional networks in the U.S. West evolve creates a murky outlook for California RPS compliance and our model representation thereof. The No CA REC Limits scenario reflects a bounding condition where a much greater amount of non-California RE resources would be potentially eligible for CA RPS compliance.

\subsection{Results and Discussions}

In this section, we present capacity and generation mix results for the nine scenarios, first for the U.S. West as a whole, and then individually for Nevada, California, and Arizona. These results are aggregated from the region-level outputs from ReEDS. As discussed in Section 2.1, ReEDS balances electricity supply and consumption within each modeling region while simultaneously

\footnotetext{
${ }^{20}$ For example, in our default representation, the average state-level UPV capital cost multiplier is 1.079 for California, 1.064 for Nevada, and 1.001 for Arizona. In our Higher CA RE Cost scenario, we multiply the corresponding default region-level values by 2 in Southern California and 1.5 in the rest of California.

${ }^{21}$ For details on the three RPS portfolio content categories, commonly referred to as "buckets," see: http://www.cpuc.ca.gov/RPS_Procurement_Rules_33/
} 
accounting for any broader state or regional interactions and/or constraints. All PV (UPV and rooftop PV) capacity results presented here are presented in DC units, while the remaining technology types are in AC units. In addition, all results presented here assume that total cumulative existing and prescribed UPV capacity is $7.9 \mathrm{GW}_{\mathrm{DC}}$ in California, $1.2 \mathrm{GW}_{\mathrm{DC}}$ in Nevada, and $1.3 \mathrm{GW}_{\mathrm{DC}}$ in Arizona. These values account for all existing sites and projects under construction included within the ABB Velocity Suite database as of April 2016 (ABB 2016). However, proposed and permitted projects are not explicitly included. Key findings, which are discussed in detail throughout this section, include:

- Renewables are estimated to compose most new capacity additions in the U.S. West. Deployment of new capacity across the broader U.S. West region of 11 states is driven primarily by clean energy policies, including state RPSs and the U.S. Environmental Protection Agency's Clean Power Plan. Cumulative UPV capacity across the U.S. West grows from a baseline of about $7 \mathrm{GW}_{\mathrm{DC}}$ in 2014 to $11-17 \mathrm{GW}_{\mathrm{DC}}$ in 2020 and $11-87$ $\mathrm{GW}_{\mathrm{DC}}$ in 2030, depending on the scenario. The largest projected installed UPV capacity across the U.S. West is achieved when future natural gas fuel prices are assumed to increase well above current prices and/or PV costs decrease rapidly.

- California offers the largest opportunity for new UPV deployment in the U.S. West through 2030. California's RPS target of 50\% by 2030 is a key driver of renewable deployment, including UPV, within California and for renewable project development in neighboring states. In particular, UPV deployment is found to be sensitive to California RPS rules for out-of-state resources. The scenario results indicate that non-California UPV resources can provide high-quality UPV resource to meet California policy requirements should market conditions favor those resources and if transmission access is available. The relative project development cost in California, which could be larger due to - among other factors - elevated permitting costs, compared to development costs in neighboring states is found to be an important component of those market conditions. Distributed PV deployment can also influence UPV deployment in California and the region as it impacts electricity sales and corresponding RPS demand for new renewable energy.

- Under the range of scenarios presented here, UPV development in Nevada is projected to reach $1.2 G W_{D C}$ of cumulative capacity by 2020 and $1.2-13.2 G W_{D C}$ by 2030, from a 2014 baseline of $0.6 G_{D C}$. Cumulative UPV capacity of greater than $4 \mathrm{GW}_{\mathrm{DC}}$ by 2030 is achieved if (1) high natural gas fuel prices and/or low PV costs are realized, or (2) the higher relative cost to develop renewable resources in California is further amplified, thus shifting renewable resource deployment to more economically-favorable adjacent states such as Nevada. Conversely, the results suggest that if the opposite conditions prevail, UPV growth in Nevada can essentially stagnate over the study period. Results suggest that multiple possibilities exist for market and/or policy conditions to be favorable for Nevada UPV deployment, but the future presence and extent of these factors is highly uncertain.

- As a fraction of total annual generation, the UPV share in Nevada meets or exceeds those in the neighboring states of California and Arizona. While Nevada is projected to remain the smallest UPV market in the Nevada-Arizona-California area on an absolute basis, the 
UPV generation share, as a fraction of in-state generation, is much more similar across the three states in 2020 and 2030.

\subsubsection{U.S. West-Wide Scenario Results}

Results for the 11 states in the U.S. West ${ }^{22}$ under our nine scenarios are presented in Figures 411 and Table 2. Figure 4 shows the U.S. West cumulative capacity, with snapshots of the 2020 and 2030 cumulative capacity in Figure 5 for the Central and bounding U.S. West scenarios (High PV Deployment on the upper end and High PV Cost on the low end). Similarly, Figure 6 presents the U.S. West generation under the Central scenario, with snapshots of the 2020 and 2030 annual generation profiles in Figure 7 for the Central and bounding U.S. West scenarios. See Appendix B for a tabulated version of the data shown in Figure 4 and Figure 6. Results for each of the sensitivity scenarios with respect to the Central scenario in 2020 and 2030 are shown in Figure 8 for the differences in cumulative capacities and in Figure 9 for the differences in generation. Snapshots of the 2020 and 2030 solar (rooftop PV, UPV, and CSP) cumulative capacity and annual generation for all scenarios are shown in Figure 10 and Figure 11, respectively. The "Other" category in these figures includes biopower, oil-gas-steam, and landfill gas. "Canada Imports" refers to net imports from Canada.

Across the U.S. West, new capacity growth through 2030 is dominated by renewable resources, as shown in Figure 4 and Figure 5. Across the full range of scenarios, cumulative UPV capacity in the U.S. West grows from a baseline of about $7 \mathrm{GW}_{\mathrm{DC}}$ in 2014 to $11-17 \mathrm{GW}_{\mathrm{DC}}$ in 2020 and $11-87 \mathrm{GW}_{\mathrm{DC}}$ in 2030 . These additions are driven primarily by RPS and CPP policies. Notably, California's RPS target of 50\% renewables as a fraction of electricity sales by 2030 enables California to yield the dominant share of the total U.S. West's cumulative UPV capacity in all years, as shown in Table 2.

Table 2. Cumulative UPV Capacity $\left(G_{D C}\right)$ for Central and U.S. West 2030 Bounding Scenarios

\begin{tabular}{|c|c|c|c|c|c|}
\hline & & U.S. West & NV & CA & $\mathbf{A Z}$ \\
\hline \multirow{3}{*}{$\frac{⿱}{\grave{N}}$} & Central & 7.2 & 0.6 & 5.0 & 1.2 \\
\hline & High PV Deployment & 7.2 & 0.6 & 5.0 & 1.2 \\
\hline & High PV Cost & 7.2 & 0.6 & 5.0 & 1.2 \\
\hline \multirow{3}{*}{ ণ్ స్ } & Central & 11.3 & 1.2 & 7.9 & 1.3 \\
\hline & High PV Deployment & 15.8 & 1.2 & 12.4 & 1.3 \\
\hline & High PV Cost & 11.3 & 1.2 & 7.9 & 1.3 \\
\hline \multirow{3}{*}{ ల్లి } & Central & 33.1 & 1.3 & 21.8 & 6.5 \\
\hline & High PV Deployment & 87.3 & 9.4 & 29.7 & 14.8 \\
\hline & High PV Cost & 11.3 & 1.2 & 7.9 & 1.3 \\
\hline
\end{tabular}

\footnotetext{
${ }^{22}$ The 11 states are Arizona, California, Colorado, Idaho, Montana, Nevada, New Mexico, Oregon, Utah, Washington, and Wyoming.
} 


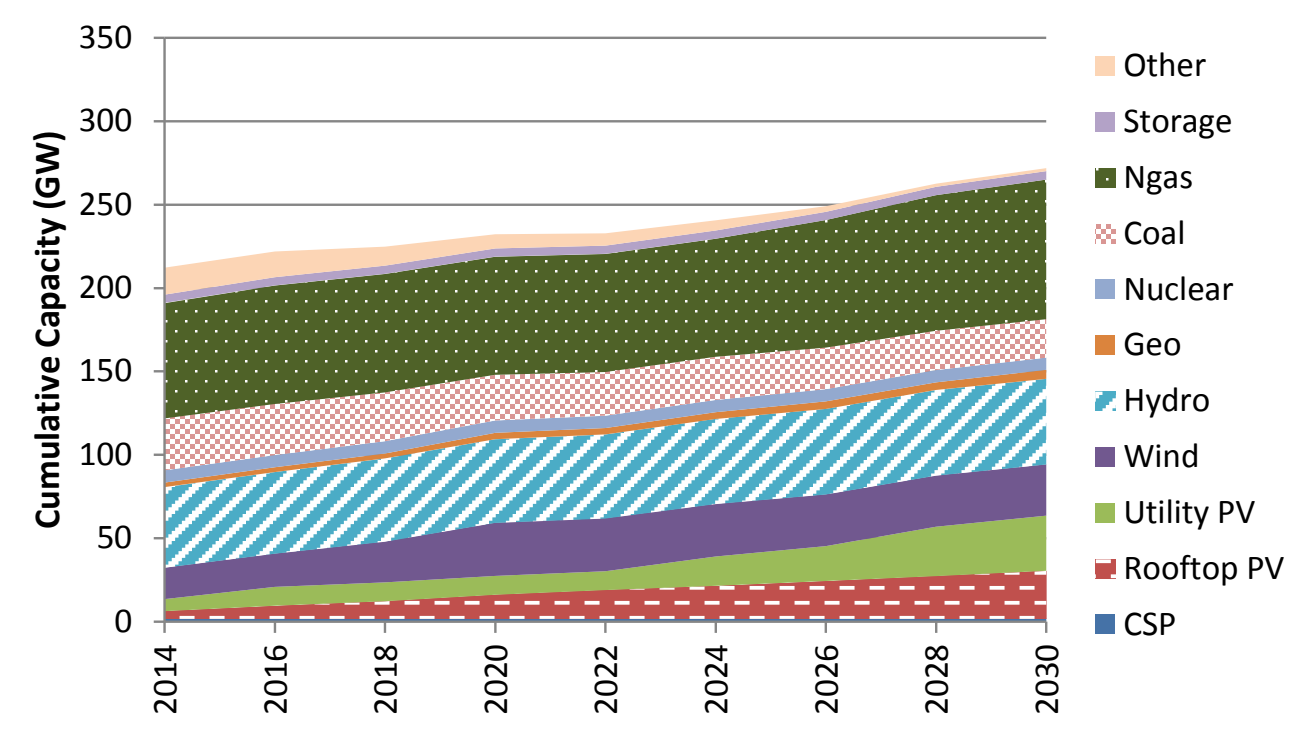

Figure 4. Central scenario U.S. West cumulative capacity

Utility PV and Rooftop PV are on a DC-basis, all others on AC-Basis

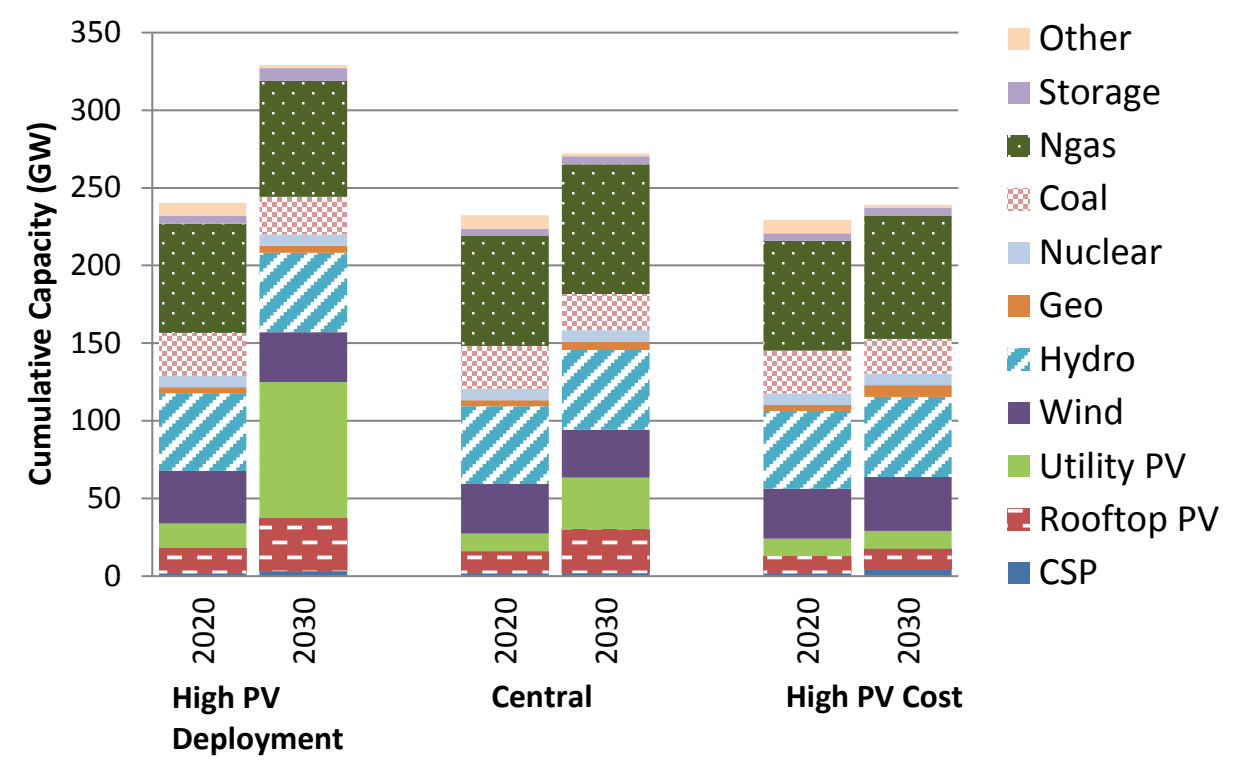

Figure 5. U.S. West cumulative capacity for Central and bounding scenarios

Note: Utility PV and Rooftop PV are on a DC-basis, all others on AC-basis

Current 2015 total generation capacity in the U.S. West exceeds North American Electric Reliability Corporation (NERC) reference reserve margins, and as a result, ReEDS finds that new capacity is not needed to meet growth of electricity consumption until the 2020s. This reflects actual system configurations in the Western Electricity Coordinating Council (WECC), which has observed planning reserve margins in excess of the NERC reference reserve margin. NERC has attributed these large reserve margins to capacity that was deployed to (1) satisfy RPS policies, and (2) meet anticipated electricity consumption growth, which was later interrupted by the economic recession (NERC 2015). Thus, new capacity additions in the results presented here 
are largely driven by policy requirements, such as the RPS and CPP, but are still influenced by the system reserve margin and growth of electricity consumption in later years.

Generation trends for the U.S. West, as shown in Figure 6 and Figure 7, reveal that renewable resources also become the leading source of generation supplied by 2030 . Across the full range of scenarios, generation from all renewables ${ }^{23}$ in the U.S. West occupies $53 \%-67 \%$ of total generation in 2030, at least half of which is comprised by wind and solar (UPV, rooftop PV, and CSP) resources. Solar alone provides $8 \%-28 \%$ of total generation, and the contribution from UPV ranges from $3 \%-20 \%$, depending on the scenario.

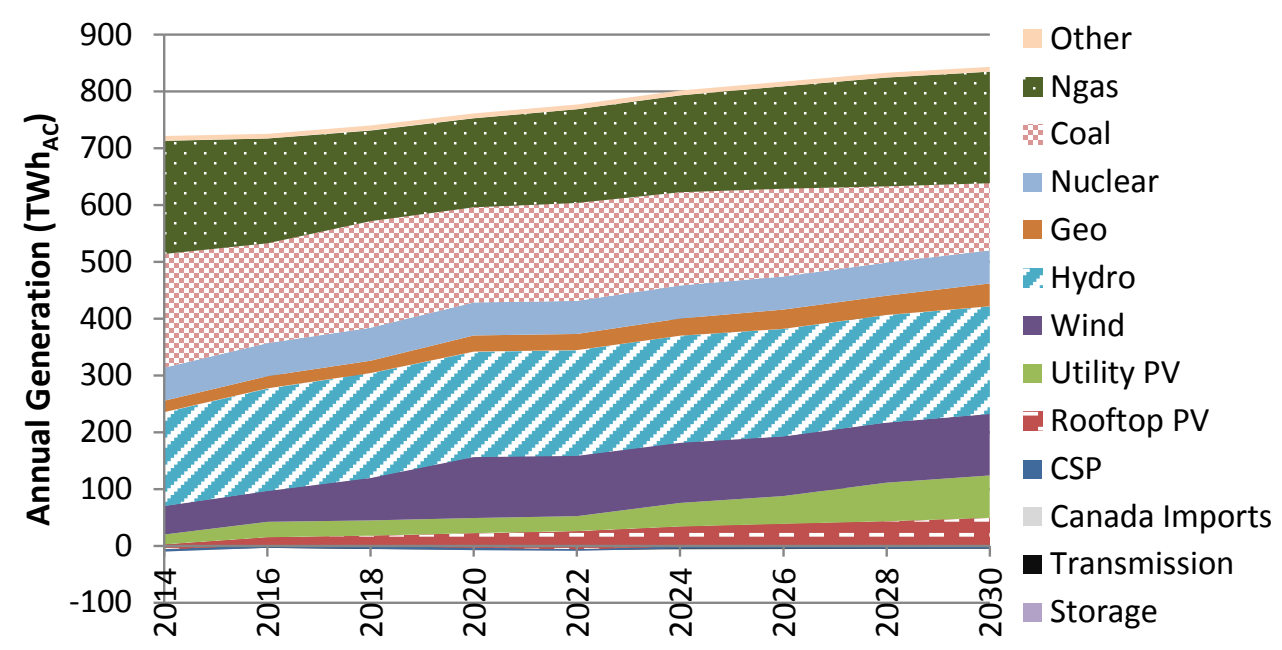

Figure 6. Central scenario U.S. West generation

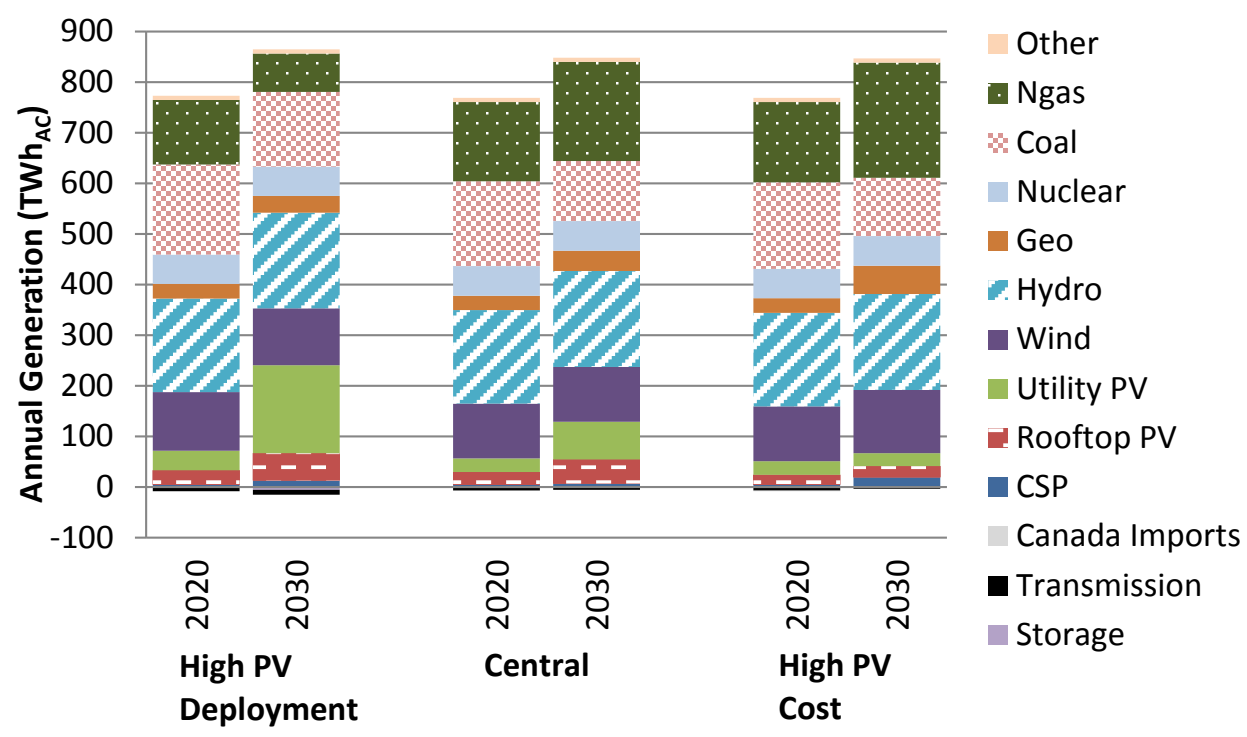

Figure 7. U.S. West annual generation for Central and bounding scenarios

\footnotetext{
${ }^{23}$ Including rooftop PV, UPV, CSP, wind, hydro, geothermal, and biomass.
} 
Under our central economic and electricity consumption assumptions in the Central scenario, natural gas capacity additions closely follow the trend in natural gas prices. Natural gas capacity in the U.S. West is deployed in early years due to low fuel prices, but then deployment halts as fuel prices recover after 2016 (based on the AEO 2016 Reference case assumptions). Natural gas deployment then grows after 2024 when fuel prices are predicted to plateau. Generation from natural gas follows a similar up-down-up cycle, as a result of these natural gas price fluctuations, as well as policies such as the CPP and RPS, which drive investments in renewable technologies that displace fossil units. For coal, both capacity and generation decline through 2030, which is driven in part by the CPP and by assumed retirements.

In addition to the CPP, RPS targets are important policies affecting UPV growth. For example, the California RPS compliance strategy impacts UPV growth in Nevada and the broader U.S. West, as shown in the No CA RPS Limits scenario in Figure 8. In this scenario, the relaxed eligibility requirements of renewable resources in the U.S. West to meet California's $50 \%$ RPS results in slightly less UPV capacity across the U.S. West (about $3 \mathrm{GW}_{\mathrm{DC}}$ in 2030 relative to the Central scenario), though we later show that Nevada sees slightly more UPV in this scenario.

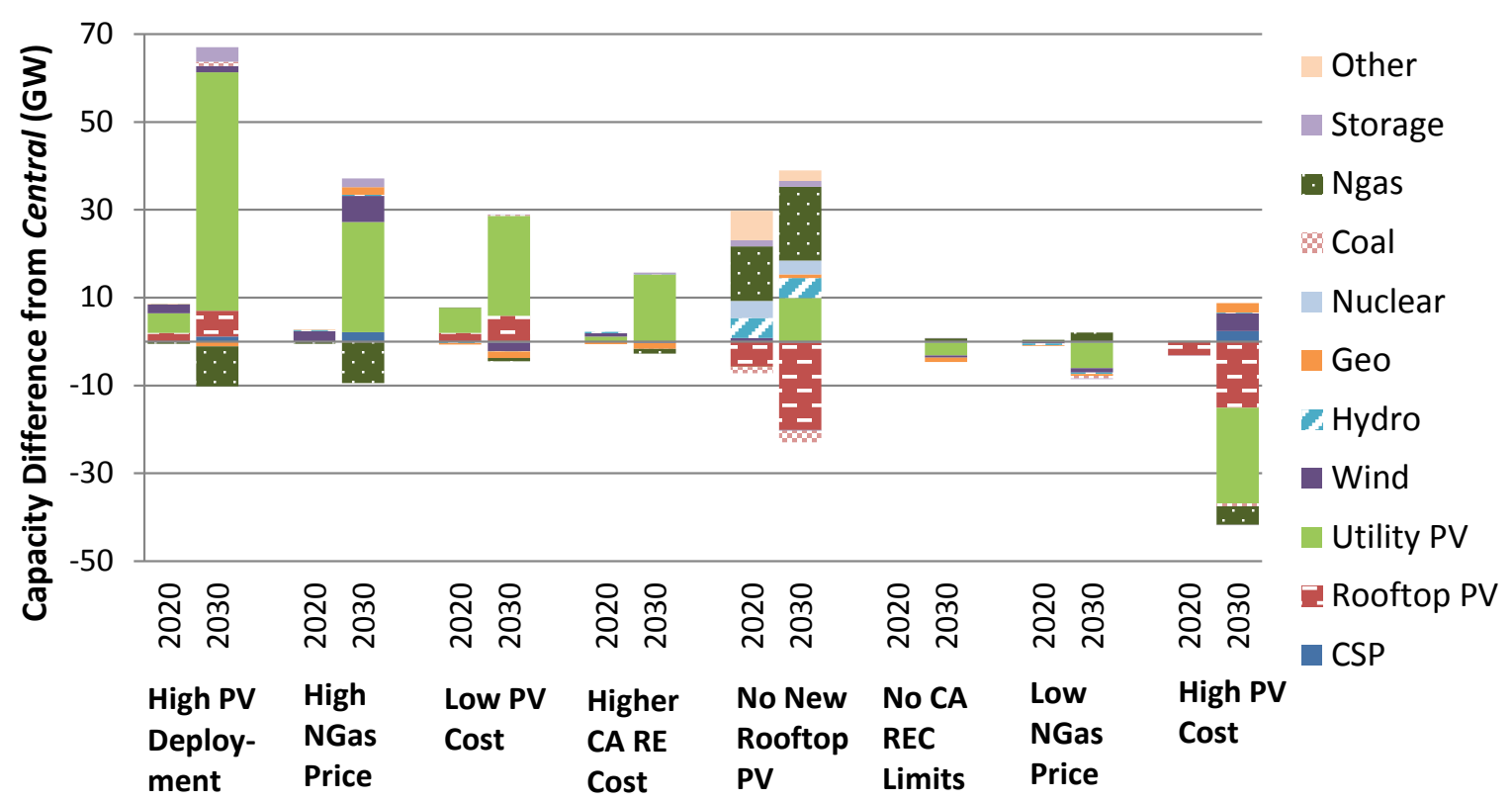

Figure 8. U.S. West cumulative capacity difference from Central scenario Utility PV and Rooftop PV are on a DC-basis; all others are on an AC-basis.

Other key drivers affecting the growth of UPV include future changes in PV costs, natural gas prices, and growth of electricity consumption. Across all scenarios, UPV growth remains low in the near term primarily because of the excess capacity relative to the NERC reference reserve margins. However, deployment sees significant growth starting around 2020 as the system begins to require new capacity and generation (Figure 10). This capacity need is driven by the push to meet the first CPP interim compliance target in 2022. In this near-term period, rooftop PV and UPV deployment tradeoff with natural gas capacity builds, depending on their relative deployment and cost assumptions. In addition, the interactions of assumed PV cost reductions and rising natural gas prices further increase the competitiveness of UPV relative to wind and 
other renewable technologies to meet these CPP-induced capacity needs. The need for additional generation is driven primarily by rising electricity consumption, which also increases the RPS demand for renewable generation.

Across scenarios, UPV growth is especially sensitive to natural gas fuel prices and the rate of future UPV price reductions, both of which impact the relative competitiveness of UPV alone and against wind and other renewable resources. This sensitivity to natural gas fuel prices and PV costs is shown in the High PV Deployment scenario, which has the largest cumulative UPV capacities (Figure 8 and Figure 10) and largest UPV generation shares (Figure 9 and Figure 11) across the U.S. West in 2020 and 2030. Natural gas prices and PV costs have similar impacts independently: high natural gas prices and low PV costs alone result in large UPV deployment and generation levels, while low natural gas prices and high PV costs result in low UPV deployment and generation levels. In addition, high natural gas prices shift capacity and generation from gas-fired units to PV, wind, and coal (High NGas Price), while high PV costs shift capacity and generation from UPV to gas-fired units and wind (High PV Cost) (Figure 8 and Figure 9). The reduction in renewable capacity and generation (including solar, wind, and geothermal) in the No CA REC Limits scenario, as shown in Figure 8 and Figure 9, is discussed in Section 3.3.3.

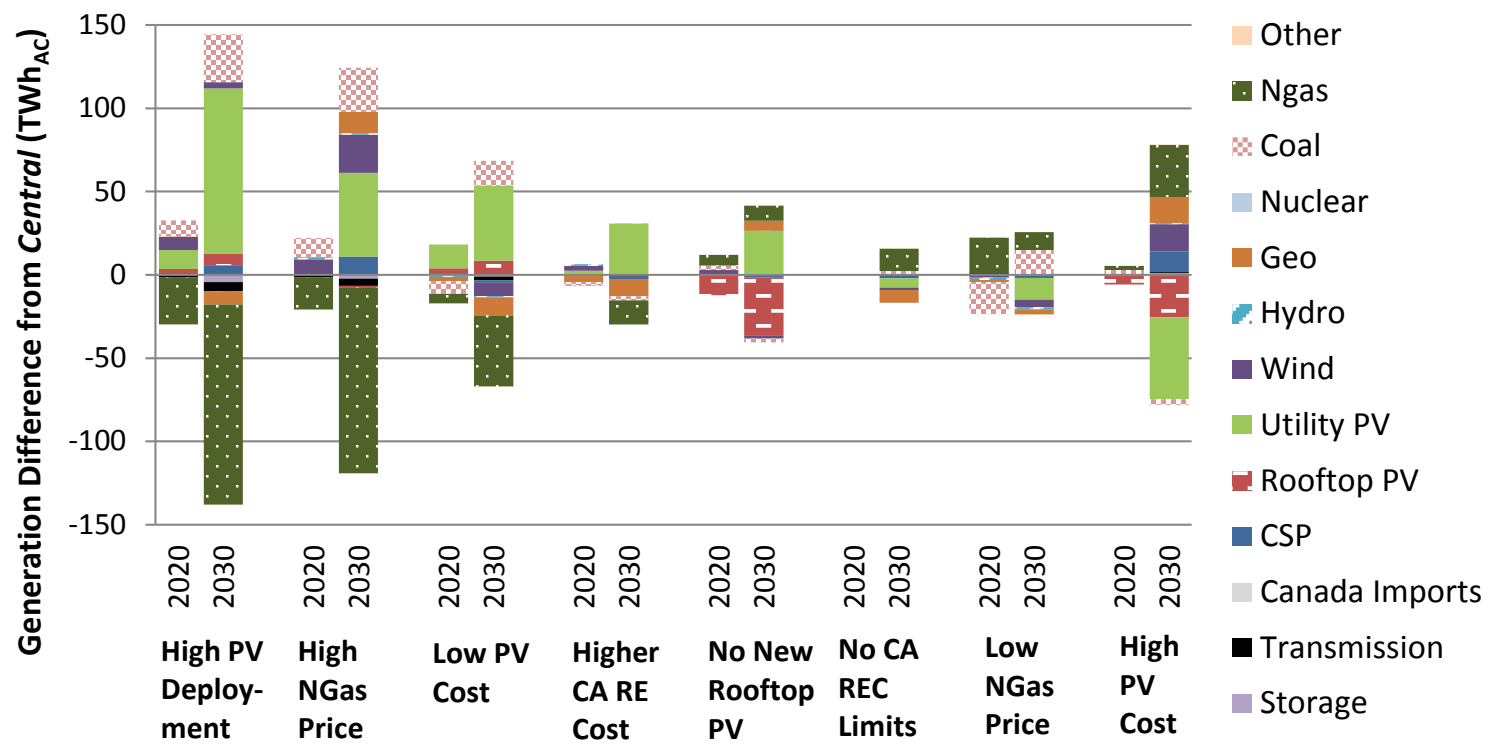

Figure 9. U.S. West annual generation difference from Central scenario 


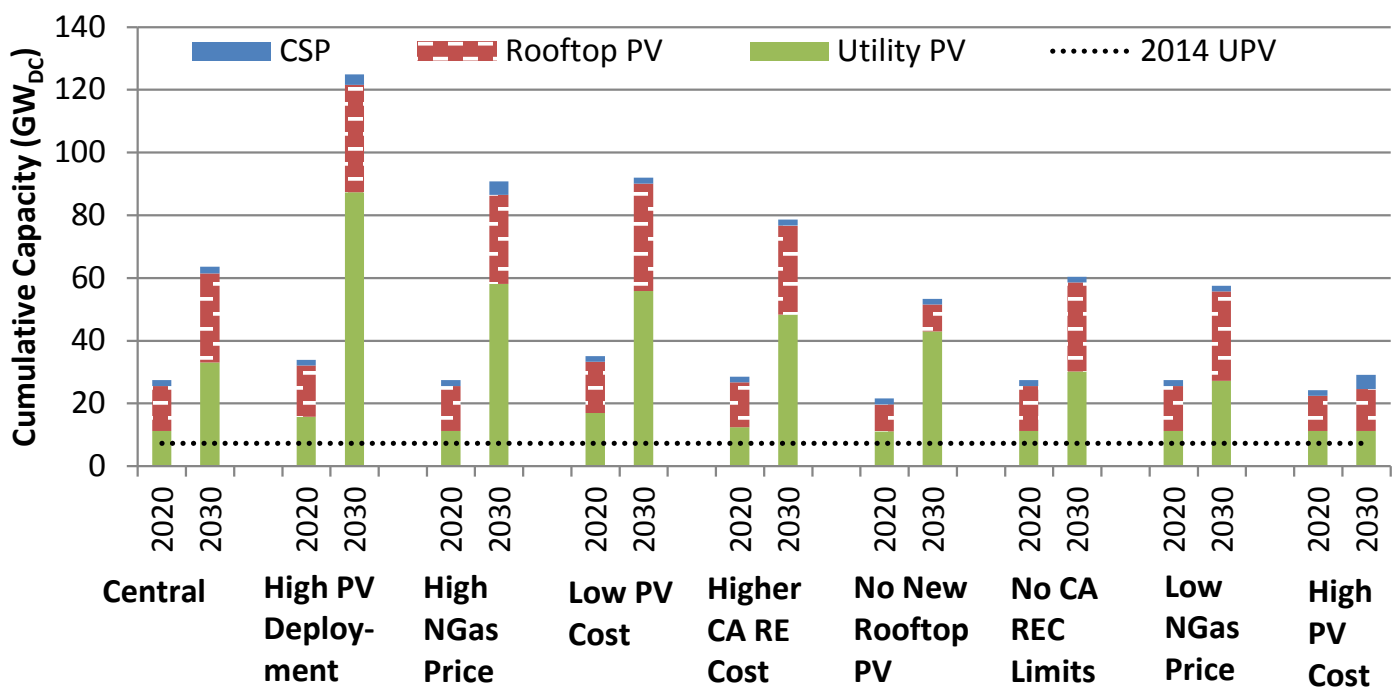

Figure 10. U.S. West cumulative solar capacity in 2020 and 2030

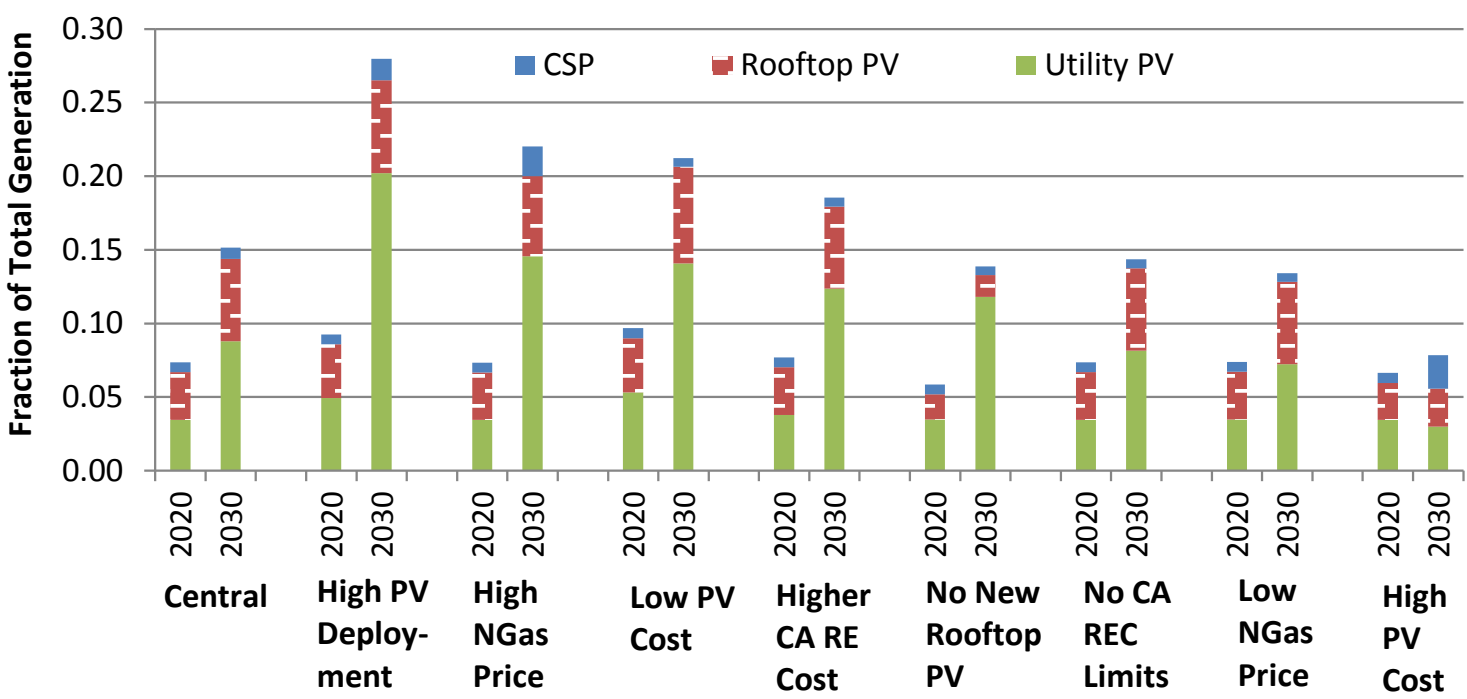

Figure 11. U.S. West solar generation as a percent of total generation in 2020 and 2030 


\subsubsection{State-Level Results}

A key objective of this study is to determine the outlook for UPV in Nevada. As shown in the state-level 2020 and 2030 cumulative capacity projections for Arizona, California, and Nevada (Figure 12), absolute solar capacity additions are greatest in California and Arizona. This is driven by the larger demand and high quality solar resource in California and Arizona, as well as California's comparatively high avoided energy prices and more-stringent RPS policy. The contribution from each solar technology (UPV, rooftop PV, and CSP) is shown separately. However, as a fraction of total annual in-state generation in Figure 13, the UPV shares in Nevada meet or exceed those of at least one of the neighboring states of California and Arizona since there is greater electricity consumption in these states. The two exceptions to this trend were in the Central and No New Rooftop PV scenarios, where Nevada saw slightly less UPV generation as a percentage of electricity consumption. In other words, while Nevada is a smaller market than Arizona and California, UPV growth is estimated to be roughly equivalent when normalized by market size, though this estimated growth is more variable across the range of scenarios in Nevada than in California or Arizona.

UPV cumulative capacity in Nevada is projected to reach up to $13.2 \mathrm{GW}_{\mathrm{DC}}$ by 2030 , from a 2014 baseline of $0.6 \mathrm{GW}_{\text {DC }}$. This upper end of $2030 \mathrm{UPV}$ deployment is achieved if (1) high natural gas fuel prices and/or low PV costs are realized, or (2) the higher relative cost to develop renewable resources in California is further amplified, thus shifting renewable resource deployment to more economically-favorable adjacent states such as Nevada (Figure 12). Conversely, the results suggest that if the opposite conditions prevail (e.g., low natural gas fuel prices or high PV costs), UPV growth in Nevada can essentially stagnate over the study period. Other factors, such as flat rooftop PV deployment trajectories (No New Rooftop PV) and a California RPS compliance strategy that is more inclusive of out-of-state resources (No CA REC Limit), only result in slightly larger UPV deployment levels in 2030 in Nevada compared to the Central scenario (Figure 12). Overall, these results suggest that multiple possibilities exist for market/policy conditions to be favorable for Nevada to see UPV deployment reach above 4 $G W_{D C}$ cumulative capacity in the mid-term (2030), but the future presence and extent of these factors is highly uncertain. In other words, the sensitivity of Nevada UPV deployment to policy and/or economic factors across these scenarios reveals a lack of a single UPV market outlookand therefore potentially a SEZ expansion plan-that is robust against multiple variables, such as natural gas prices, UPV costs, policy implications, and regional dynamics. 

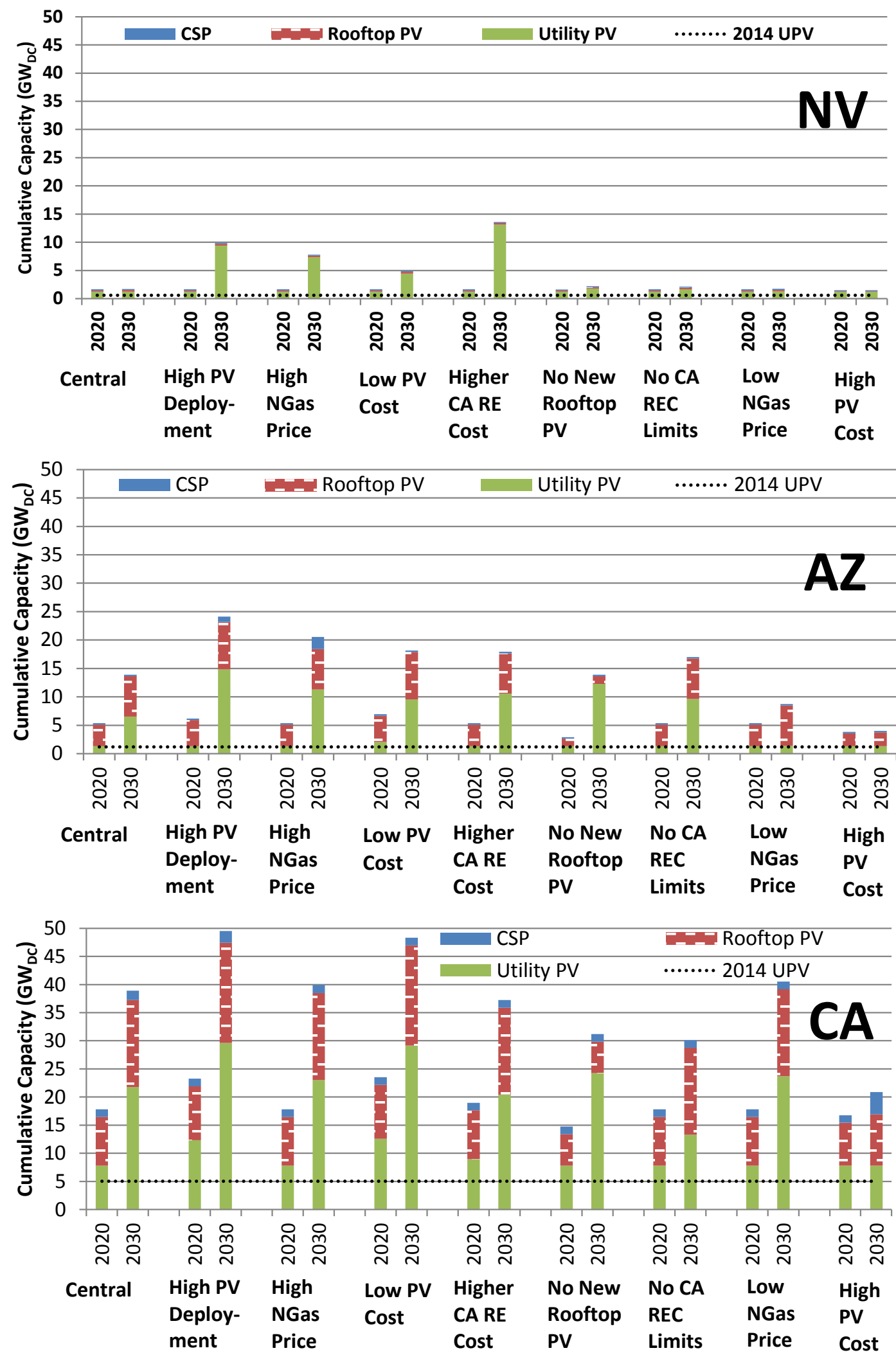

Figure 12. State-level cumulative solar capacity in 2020 and 2030 

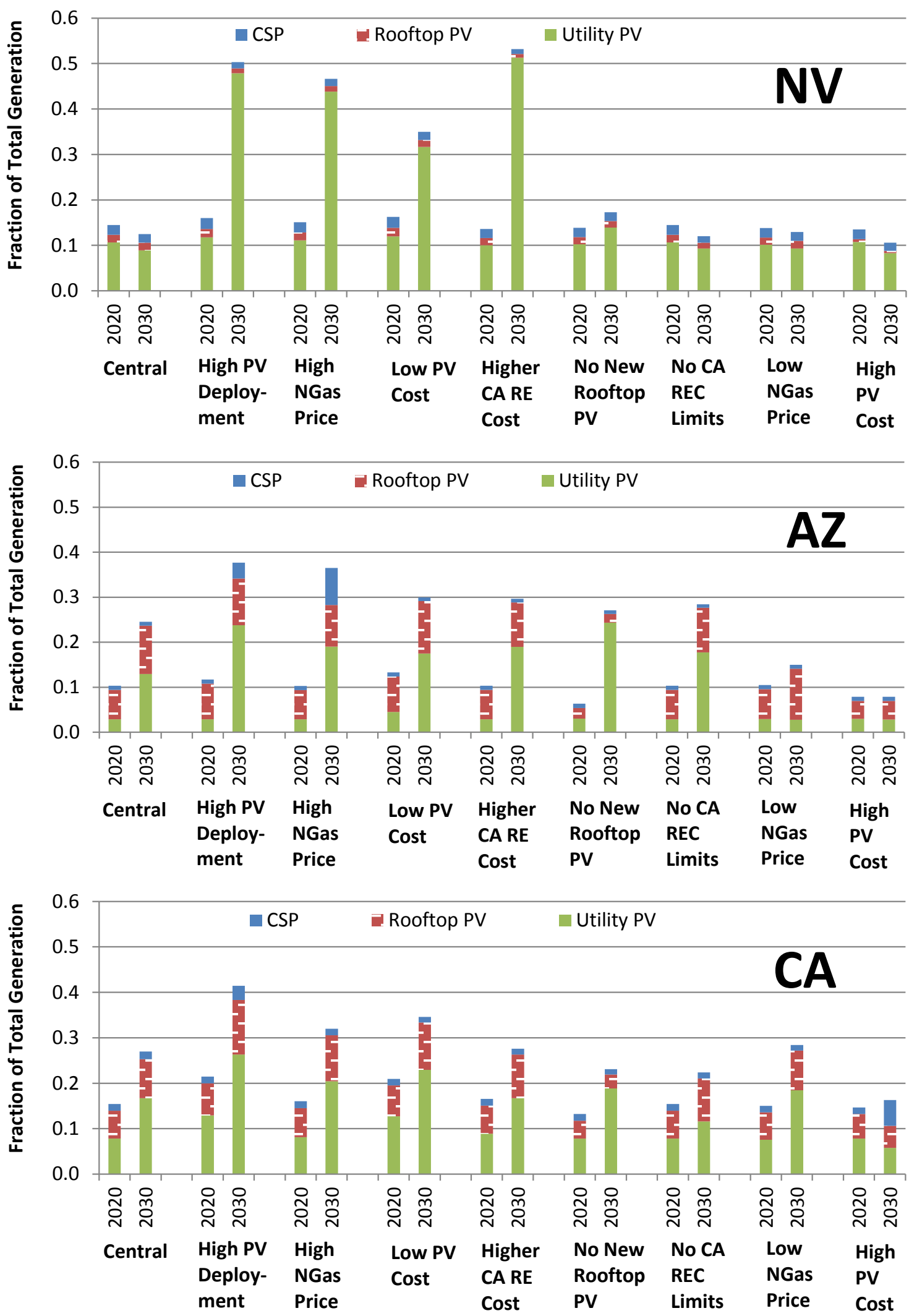

Figure 13. State-level solar generation as a percent of total generation in $\mathbf{2 0 2 0}$ and 2030 
All scenarios see very little UPV deployment in the near term (through 2020), with cumulative UPV capacity reaching $1.2 \mathrm{GW}_{\mathrm{DC}}$ by 2020 in every scenario. However, as previously noted, ReEDS only accounts for existing and under-construction projects in its model representation. For example, the BLM has approved solar energy projects in southern Nevada that are in various stages of pre-construction, construction, or have completed construction. This includes three utility-scale solar energy projects in the Dry Lake SEZ that were approved in December 2014 and would generate a combined total of $480 \mathrm{MW}_{\mathrm{DC}}$. The BLM has 10 grandfather status applications for utility-scale solar energy projects in southern Nevada, of which four are currently being processed for environmental analysis by the BLM. While many applications for utility-scale solar energy projects will not result in actual UPV deployment, they are indicative of a high level of solar energy industry interest in southern Nevada. Additional sources of error in the estimates presented here include the modeling limitations highlighted in Section 2.2.

Table 3 summarizes the total UPV new capacity deployment for 2015-2020 and 2021-2030 by each state, for the three states as a whole, and for the entire U.S. West for all years in the relevant period. This table reveals that (1) the majority of all U.S. West UPV deployment occurs within these three states and (2) scenario-based differences do not appear for new UPV builds in Nevada until the mid-term outlook (2021-2030). Across the full range of our scenarios, the total new UPV deployment in Nevada is uniform at $0.7 \mathrm{GW}_{\mathrm{DC}}$ for the period from 2015 to 2020 , and ranges from $0-11.9 \mathrm{GW}_{\mathrm{DC}}$ for the period from 2021 to 2030 , depending on the scenario. The key 2021-2030 differences are driven by PV costs, natural gas fuel prices, and the relative California renewable energy project development cost, the last of which is discussed in more detail in Section 3.3.3. Table 4 summarizes the range of corresponding land area requirement for the Nevada deployment values in Table 3, assuming land use factors from 7 to 10 acres/ $\mathrm{MW}_{\mathrm{DC}}$ (Ong et al. 2013). For Nevada, between about 4,600 and 6,500 acres would be required for new UPV capacity builds between 2015 and 2020, and between 0 and over 119,000 acres would be required for new UPV capacity builds between 2021 and 2030, depending on the scenario and land use factor. 
Table 3. Statewide and Total UPV New Deployment per Time Period (GW

\begin{tabular}{|c|c|c|c|c|c|c|c|c|c|c|}
\hline & \multicolumn{4}{|c|}{ 2015-2020 } & \multirow[b]{2}{*}{$\begin{array}{l}\text { U.S. } \\
\text { West } \\
\text { Total }\end{array}$} & \multicolumn{4}{|c|}{ 2021-2030 } & \multirow[b]{2}{*}{$\begin{array}{l}\text { U.S. } \\
\text { West } \\
\text { Total }\end{array}$} \\
\hline Scenario & $A Z$ & CA & NV & $\begin{array}{l}\text { Three- } \\
\text { State } \\
\text { Total }\end{array}$ & & $\mathbf{A Z}$ & CA & NV & $\begin{array}{l}\text { Three- } \\
\text { State } \\
\text { Total }\end{array}$ & \\
\hline $\begin{array}{l}\text { High PV } \\
\text { Deployment }\end{array}$ & 0.1 & 7.3 & 0.7 & 8.1 & 8.6 & 13.5 & 17.3 & 8.2 & 39.0 & 71.5 \\
\hline High NGas Price & 0.1 & 2.8 & 0.7 & 3.6 & 4.1 & 10.0 & 15.2 & 6.1 & 31.3 & 46.8 \\
\hline Low PV Cost & 0.9 & 7.6 & 0.7 & 9.1 & 9.8 & 7.5 & 16.6 & 3.2 & 27.3 & 38.8 \\
\hline Higher CA RE Cost & 0.1 & 4.0 & 0.7 & 4.8 & 5.2 & 9.2 & 11.5 & 11.9 & 32.6 & 35.9 \\
\hline $\begin{array}{l}\text { No New Rooftop } \\
\text { PV }\end{array}$ & 0.1 & 2.8 & 0.7 & 3.6 & 4.1 & 11.0 & 16.4 & 0.6 & 27.9 & 31.8 \\
\hline Central & 0.1 & 2.8 & 0.7 & 3.6 & 4.1 & 5.2 & 14.0 & 0.0 & 19.2 & 21.7 \\
\hline No CA REC Limits & 0.1 & 2.8 & 0.7 & 3.6 & 4.1 & 8.3 & 5.5 & 0.5 & 14.3 & 18.9 \\
\hline Low NGas Price & 0.1 & 2.8 & 0.7 & 3.6 & 4.1 & 0.1 & 15.9 & 0.0 & 16.0 & 16.0 \\
\hline High PV Cost & 0.1 & 2.8 & 0.7 & 3.6 & 4.1 & 0.0 & 0.0 & 0.0 & 0.0 & 0.0 \\
\hline
\end{tabular}

Table 4. Total Acres Required for Nevada UPV New Deployment per Time Period

\begin{tabular}{l|ll}
\hline Scenario & $\mathbf{2 0 1 5 - 2 0 2 0}$ & $\mathbf{2 0 2 1 - 2 0 3 0}$ \\
\hline High PV Deployment & $4,598-6,569$ & $57,411-82,015$ \\
\hline High NGas Price & $4,598-6,569$ & $42,863-61,233$ \\
\hline Low PV Cost & $4,598-6,569$ & $22,379-31,971$ \\
\hline Higher CA RE Cost & $4,598-6,569$ & $83,372-119,102$ \\
No New Rooftop PV & $4,598-6,569$ & $4,008-5,725$ \\
\hline Central & $4,598-6,569$ & $99-141$ \\
\hline No CA REC Limits & $4,598-6,569$ & $3,181-4,544$ \\
\hline Low NGas Price & $4,598-6,569$ & $292-417$ \\
High PV Cost & $4,598-6,569$ & $0-0$ \\
\hline
\end{tabular}




\subsubsection{State-Level UPV Sensitivity to Broader Regional Dynamics}

UPV deployment across the states of California, Arizona, and Nevada is sensitive to multiple factors that reflect broader regional dynamics. These include policies that could severely limit rooftop PV deployment (No New Rooftop PV) ${ }^{24}$ California RPS rules regarding out-of-state resources for RPS compliance (No CA REC Limits), and higher costs to develop renewable resources in California. Key differences were observed in the UPV and rooftop PV deployment tradeoffs both within a given state and between the states of California, Arizona, and Nevada in these three scenarios. First, the No New Rooftop PV scenario resulted in greater UPV deployment within each of these three states, with the largest relative increase in UPV ( $88 \%$ increase in 2030 compared to the Central scenario) seen by Arizona.

Secondly, the No CA REC Limits shifted development of in-state California resources to elsewhere within the U.S. West, resulting in $40 \%$ lower cumulative UPV capacity in California in 2030 compared with the Central scenario. Here again, Arizona realizes the greatest relative growth in UPV deployment, with $48 \%$ more cumulative UPV capacity in 2030 than in the Central scenario; Nevada saw a corresponding increase of $35 \%$. This indicates that Nevada and Arizona can provide high-quality UPV resource for the broader region, should policies allow out-of-state resources to contribute toward RPS compliance in a different state, such as California in this case. We also note that, given the past and potential ongoing expansion of CAISO and the EIM in the U.S. West, the results for the broader region should be taken into consideration in this No CA REC Limits scenario. For example, the U.S. West sees slightly less overall renewable capacity deployment and generation in this scenario compared the Central scenario (Figure 8 and Figure 9). By allowing more renewables to be eligible for California's RPS compliance, the incremental amount of renewable energy needed across the U.S. West is relaxed, resulting in less overall renewable capacity and generation as compared to the Central scenario. See Appendix A for more discussion on these broader regional interactions.

Finally, the Higher CA RE Cost scenario had the greatest impact on UPV deployment in Nevada of any scenario, resulting in 1-3 orders of magnitude more average annual UPV deployment in Nevada in the 2021-2030 period than any other scenario (1191 $\mathrm{MW}_{\mathrm{DC}} / \mathrm{yr}$ versus $0-820$ $\mathrm{MW}_{\mathrm{DC}} / \mathrm{yr}$, see Table 3), and 1 order of magnitude more $2030 \mathrm{UPV}$ cumulative capacity in Nevada than the Central scenario ( $13 \mathrm{GW}_{\mathrm{DC}}$ versus $1.3 \mathrm{GW}_{\mathrm{DC}}$, see Figure 12). However, results from the High PV Deployment and High NGas Price scenarios, which saw significantly larger 2030 cumulative capacities in Nevada than the Central scenario (Figure 12), suggest that PV costs and natural gas fuel price assumptions are likely just as important to the overall and statelevel UPV deployment outlook as the market and policy factors examined here.

Transmission line flows in the California, Nevada, Arizona three-state area can vary significantly based on UPV deployment levels and time of day. Intra- and inter-regional flows, along with many other factors, can impact the preference and ability of a given state to develop in-state resources versus exporting out-of-state resource. For example, a study investigating import/export, curtailment, cycling, and production cost impacts from a low-carbon California grid with renewable penetrations levels above $50 \%$ found that, from a carbon reduction and

\footnotetext{
${ }^{24}$ Possibilities include, but are not limited to, futures where rate structures are severely unfavorable to rooftop PV owners, NEM is eliminated, or other distributed PV policy measures that disincentive rooftop PV deployment are implemented.
} 
curtailment perspective, the state's preference between a future system with diverse out-of-state resources versus a future system with high deployment of in-state solar resources depends on the level of flexibility (Brinkman et al. 2016). No conclusive findings were observed in the ReEDS line flow results. More research using higher resolution analysis is needed to better understand the inter- and intra-regional transmission impacts of UPV deployment under a wide range of scenarios. We refer the reader to the ongoing work with the California Renewable Energy Transmission Initiative 2.0 (RETI 2.0) (25 $^{25}$ and the BLM 368 Corridor (White et al. 2016) studies, which are identifying and examining transmission corridors to help California reach its RPS goals while considering environmental constraints.

\subsubsection{Comparison with Other Published UPV Projections}

To provide a more comprehensive outlook of UPV growth in the U.S. West, we place the UPV deployment estimates from our nine scenarios modeled in ReEDS within the context of a variety of other projections. These include findings from EIA, Bloomberg New Energy Finance, Western Electricity Coordinating Council, Greentech Media Research, and Solar Energy Industries Association. These sources and their relevant analyses are summarized in Table 5. The EIA, BNEF, and GTM/SEIA projections include the effects from the ITC extensions, Nevada NEM changes, and CPP. ${ }^{26}$

\footnotetext{
${ }^{25} \mathrm{http}: / / w w w . e n e r g y . c a . g o v / r e t i /$

${ }^{26}$ However, a direct comparison cannot be made with these other sources, as we do not know all assumptions and methods used for their projections.
} 
Table 5. Data Sources for Solar PV Comparison

\begin{tabular}{l|l|l|l}
\hline $\begin{array}{l}\text { Name used in } \\
\text { Figure 14 }\end{array}$ & Organization(s) & Source & Notes \\
\hline AEO 2016 & EIA & $\begin{array}{l}\text { AEO 2016 } \\
\text { (EIA 2016) }\end{array}$ & Reference scenario \\
\hline BNEF & $\begin{array}{l}\text { Bloomberg New Energy } \\
\text { Finance (BNEF) }\end{array}$ & BNEF 2016b & \\
\hline GTM/SEIA & $\begin{array}{l}\text { Greentech Media } \\
\text { Research (GTM) and } \\
\text { Solar Energy Industries } \\
\text { Association (SEIA) }\end{array}$ & $\begin{array}{l}\text { GTM and } \\
\text { SEIA 2016b }\end{array}$ & \\
\hline WECC & $\begin{array}{l}\text { Western Electricity } \\
\text { Coordinating Council } \\
\text { (WECC) }\end{array}$ & $\begin{array}{l}\text { 2024 Common } \\
\text { Case v1.5 } \\
\text { (WECC 2015) }\end{array}$ & $\begin{array}{l}\text { Single year projection for 2024 only; } \\
\text { bonvert capacity and generation to DC- } \\
\text { basing an assumed DC-to-AC } \\
\text { inverter ratio of 1.2 }\end{array}$ \\
\hline
\end{tabular}

A comparison of total PV cumulative capacity trends for the 11 states in the U.S. West are shown in Figure 14. Similar state-level total PV and UPV cumulative capacity comparisons are provided in Appendix C. In these plots, the ReEDS Central scenario is shown as a single line, and the full range of deployment across all other ReEDS scenarios is captured in the shaded area. As shown in these figures, the total PV and UPV capacity trends from our nine scenarios capture a wide range of deployment possibilities. Across our range of scenarios, ReEDS projects total PV (rooftop PV and UPV) cumulative capacity in the U.S. West from a baseline of $12 \mathrm{GW}_{\mathrm{DC}}$ in 2014, growing to about 20-33 $\mathrm{GW}_{\mathrm{DC}}$ in 2020 and $25-122 \mathrm{GW}_{\mathrm{DC}}$ in 2030 (Figure 14). However, the projections from BNEF and GTM/SEIA estimate larger and/or more rapid deployment in the near term than even our most-favorable ReEDS scenarios, especially in California and Nevada in 2020 (Appendix C). As shown in Figure 14, GTM/SEIA projects a 2020 U.S. West total PV cumulative capacity of $51 \mathrm{GW}_{\mathrm{DC}}$, over $50 \%$ higher than the largest ReEDS scenario 2020 projection. On the other hand, the AEO and WECC projections estimate lower PV deployment in the 2024-2030 period. In addition, while the ReEDS projections see delayed PV growth in the very near term compared to some of the other estimates, once growth does occur, the growth rate is similar to many of the other estimates, particularly among the more aggressive ReEDS scenarios, as indicated in Figure 14. 


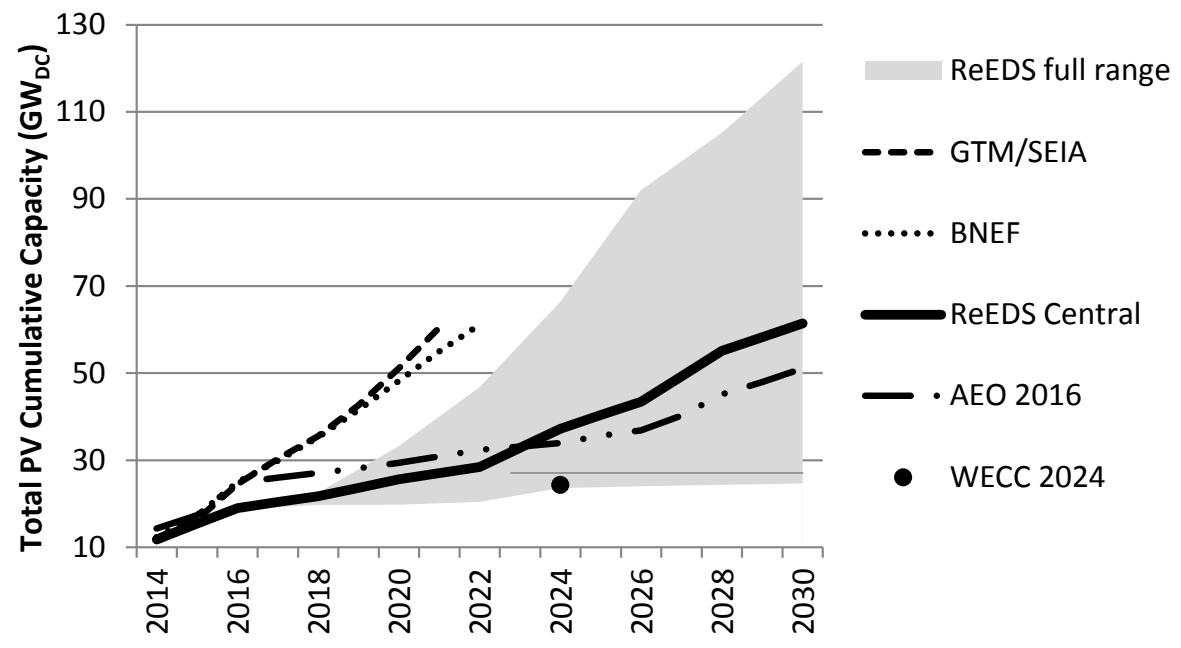

Figure 14. U.S. West-wide total PV cumulative capacity

The large spread across the various projections highlights two important caveats to this work: (1) our scenarios with more favorable UPV conditions may be more aligned with industry or other projections than our Central scenario, and (2) there is a high degree of uncertainty around all UPV projections due to uncertain policy futures and modeling differences and limitations. The ReEDS projections may potentially differ from other published projections, especially between state-level projections for California and Nevada and in the nearer-term, because of a range of potential factors. These include the caveats presented in Section 2.2, such as ReEDS' lack of foresight of future power system conditions, its inability to model individual decision-makers, and incomplete linkage with the broader energy economy, which prevents ReEDS from capturing additional local decision-making factors and value streams that could incentivize greater PV deployment. In addition, specific reasons that our ReEDS projections may have less rapid and/or lower UPV deployment include:

- ReEDS cannot model energy policies (e.g., RPS, REC trading policies, and CPP) perfectly, and the uncertainty of many of these policies, as well as broader regional market factors, further complicates the modeling of these policy and regional dynamics. For example, different assumptions regarding California's RPS compliance strategy, which may be the case with some of the other projections reported here, could yield different UPV deployment estimates.

- ReEDS is a deterministic least-cost model and does not reflect any potential hedge value of PV against anticipated natural gas prices or other market factors. Real investors and utility planners might consider these factors in their procurement decisions.

- ReEDS does not capture all non-regulatory drivers or emerging markets, such as UPV demand from corporate and industrial customers who are aiming to meet their electricity consumption with a high share of renewable resources (Wiser Capital 2015). These sources could contribute additional demand for UPV deployment.

- Actual UPV cost reductions, or alternatively, increases in natural gas fuel prices or the cost of other competing generation options, could exceed from those modeled here. However, our scenarios span multiples PV cost and natural gas fuel price trajectories to capture a wide range of future possibilities. 
- ReEDS does not account for siting challenges or environmental considerations that could eliminate some UPV development in sensitive areas. Although in reality, such capacity may instead shift to an alternative location, such as from California to Nevada.

As previously mentioned, ReEDS does not forecast the future, but instead provides a framework to evaluate the tradeoffs and impacts of technological development, policy changes, or economic conditions on the future of the electricity system. Thus, the results presented here should not be interpreted as predictions for the future. Instead, the differences between the scenarios reveal important policy, economic, and market impacts that drive the high-level qualitative trends. 


\section{Summary}

The BLM has historically designated SEZs to facilitate UPV development on federal lands. The solar energy market analysis presented in this report will be used by the BLM's Las Vegas and Pahrump Field Offices as part of the resource management plan revision to consider designating new or expanded SEZs, per the process outlined in BLM's Western Solar Plan. One component in this process is to assess whether the regional market exhibits a measurable demand for the additional generation from UPV that the zone or zones could provide.

The analysis uses NREL's ReEDS electricity capacity expansion model to estimate near- (2020) and mid-term (2030) UPV deployment and generation trends. We focus on three spatial extents: (1) Nevada only, (2) the three-state area of Nevada, California, and Arizona to capture important UPV deployment tradeoffs between these areas, and (3) the U.S. West-including Arizona, California, Colorado, Idaho, Montana, Nevada, New Mexico, Oregon, Utah, Washington, and Wyoming - to understand the broader trends across the region. We project UPV growth under a range of future technology, market, and policy conditions. Altogether nine scenarios are modeled using distinct assumptions for PV technology costs, natural gas prices, and regional policy and economic sensitivities. Key findings include:

- Renewables are estimated to make up the majority of new capacity additions in the U.S. West. Deployment of new capacity across the broader U.S. West region of 11 states is driven primarily by clean energy policies, including state RPSs and the U.S. Environmental Protection Agency's Clean Power Plan, as the policies existed at the time of this study. Total capacity in the region is in excess of the North American Electric Reliability Corporation (NERC) reference reserve margins. As a result, we find that new capacity resources are not needed to meet resource adequacy or electricity consumption growth in the near term in most regions but are instead deployed to meet policy requirements. However, deployment is still influenced by the system reserve margin and growth of electricity consumption in later years. Other factors affecting the growth of UPV include future changes in PV costs and natural gas prices. Cumulative UPV capacity across the U.S. West grows from a baseline of about $7 \mathrm{GW}_{\mathrm{DC}}$ in 2014 to $11-17$ $\mathrm{GW}_{\mathrm{DC}}$ in 2020 and $11-87 \mathrm{GW}_{\mathrm{DC}}$ in 2030 , depending on the scenario. The largest projected installed UPV capacity across the U.S. West is achieved when future natural gas fuel prices are assumed to increase well above current prices and/or PV costs decrease rapidly.

- California offers the largest opportunity for new UPV deployment in the U.S. West through 2030. From a 2014 baseline of approximately $5 \mathrm{GW}_{\mathrm{DC}}$, deployment of UPV in California reaches 8-13 GW $\mathrm{GC}_{\text {DC }}$ of cumulative UPV capacity in 2020 and 8-30 $\mathrm{GW}_{\mathrm{DC}}$ of cumulative capacity in 2030 depending on the scenario. California's RPS target of 50\% by 2030 is a key driver of renewable deployment, including UPV, within California and for renewable project development in neighboring states. In particular, UPV deployment is found to be sensitive to California RPS rules for out-of-state resources. The scenario results indicate that non-California UPV resources can provide high-quality UPV resource to meet California policy requirements should market conditions favor those resources and if transmission access is available. The relative project development cost in California, which reflects higher permitting costs in our sensitivity case, compared to 
development costs in neighboring states is found to be an important component of those market conditions. Distributed PV deployment can also influence UPV deployment in California and the region as it impacts electricity sales and corresponding RPS demand for new renewable energy.

- Under the range of scenarios presented here, UPV development in Nevada is projected to reach $1.2 G W_{D C}$ of cumulative capacity by 2020 and $1.2-13.2 G W_{D C}$ by 2030, from a 2014 baseline of $0.6 G W_{D C}$. Cumulative UPV capacity of greater than $4 \mathrm{GW}_{\mathrm{DC}}$ by 2030 is achieved if (1) high natural gas fuel prices and/or low PV costs are realized or (2) the higher relative cost to develop renewable resources in California is further amplified, thus shifting renewable resource deployment to more economically-favorable adjacent states such as Nevada. Conversely, the results suggest that if the opposite conditions prevail, UPV growth in Nevada can essentially stagnate over the study period. The corresponding land area required for new UPV deployment in these scenarios is about 4,600-6,500 acres for new UPV capacity builds between 2015 and 2020, and 0-119,000 acres for new UPV capacity builds between 2021 and 2030, assuming land use factors of 7-10 acres/MW $\mathrm{MC}_{\mathrm{DC}}$. Results indicate that multiple possibilities exist for market conditions, policy conditions, or both to be favorable for UPV deployment in Nevada, but the future presence and extent of these factors is highly uncertain. In other words, the sensitivity of UPV deployment in Nevada to policy and economic factors across these scenarios reveals a lack of a single UPV market outlook - and therefore potentially a SEZ expansion plan - that is robust against multiple variables, such as natural gas prices, UPV costs, policy implications, and regional dynamics.

- As a fraction of total annual generation, the UPV share in Nevada meets or exceeds those in at least one of the neighboring states of California and Arizona for most (but not all) of the scenarios. While Nevada is projected to remain the smallest UPV market in the Nevada-Arizona-California area on an absolute basis, the UPV generation share, as a fraction of in-state generation, is more similar across the three states in 2020 and 2030. However, this estimated growth is more variable across the range of scenarios in Nevada than it is in California or Arizona.

This scenario analysis captures important technology, resource, and policy tradeoffs on the deployment of UPV in Nevada and the broader U.S. West. We find a large range of UPV and total solar deployment possibilities in the U.S. West across our nine scenarios, but a comparison of our results with other published projections indicate that an even wider range is possible. Under the range of scenarios analyzed in this study, ReEDS projects a range of total PV (rooftop PV and UPV) cumulative capacity in the U.S. West of 20-33 $\mathrm{GW}_{\mathrm{DC}}$ in 2020 and $25-122 \mathrm{GW}_{\mathrm{DC}}$ in 2030, from a baseline of $12 \mathrm{GW}_{\mathrm{DC}}$ in 2014. Some projections report 2020 total PV cumulative capacity estimates as high as $51 \mathrm{GW}_{\mathrm{DC}}$, over 50\% higher than the largest ReEDS scenario 2020 projection. However, other projections estimate lower PV deployment in the 2024-2030 period. In addition, while the ReEDS projections see delayed PV growth in the very near term compared to some of the other estimates, once growth does occur, the growth rates are similar to many of the other estimates, particularly among the more aggressive ReEDS scenarios.

The wide range of deployment estimates highlights significant uncertainties in all projections, including the possibility for much greater and more rapid UPV deployment than is estimated in our modeling. Possible causes for these differences in UPV projections include (1) policy-related 
modeling limitations and uncertainty, and (2) modeling differences related to economic, social, and environmental factors. First, ReEDS makes decisions without foresight of future policy, market, or power system conditions, especially as they relate to CPP and RPS compliance policies and the response of investors to changing tax credit policies. Second, UPV cost reductions assumed by other sources may exceed those assumed by ReEDS. The model also takes a system-wide least-cost optimization approach, which prevents it from capturing behavior that is profit-maximizing or other local decision-making factors and preferences, such as voluntary or emerging markets for UPV from non-traditional customers such as corporate and industrial entities. Also, ReEDS is unable to account for impacts from the broader U.S. or global energy economy, and its reduced form representation of generation dispatch cannot capture the full set of economic components and subtleties that exist in real-world electricity markets. Finally, ReEDS does not account for supply chain constraints or siting challenges and environmental considerations that could slow or eliminate UPV development, or alternatively in the case of the latter, shift deployment to different geographic locations.

Another potential source for differences is the accounting of projects in the development pipeline. All modeling results presented here account for existing projects and projects under construction as of April 2016 (ABB 2016), which include UPV capacity of $7.9 \mathrm{GW}_{\mathrm{DC}}$ in California, 1.2 $\mathrm{GW}_{\mathrm{DC}}$ in Nevada and 1.3 $\mathrm{GW}_{\mathrm{DC}}$ in Arizona. However, these data do not include proposed or permitted projects. For example, the BLM has approved solar energy projects in southern Nevada that are in various stages of pre-construction or construction, or which have completed construction. This includes three utility-scale solar energy projects in the Dry Lake SEZ that were approved in December 2014 and which would generate a total of $480 \mathrm{MW}_{\mathrm{DC}}$. The BLM has 10 grandfather status applications for utility-scale solar energy projects in southern Nevada, of which four are currently being processed for environmental analysis by the BLM. While many applications for utility-scale solar energy projects will not result in actual UPV deployment, they are indicative of a high level of solar energy industry interest in southern Nevada.

Given the sensitivity of UPV deployment to the regional compliance strategy for the California RPS, future work could evaluate the intra-state and interstate details at a finer spatial and temporal resolution to better understand the impact of transmission and market factors on statelevel deployment and generation trends.

While there are inherent methodological and data limitations in the development of any future projection, we use a self-consistent modeling framework and a range of scenarios to provide data estimates of UPV deployment in the U.S. West. Our range of scenario projections, in combination with estimates from many others, can be used to inform BLM planning activities. 


\section{References}

ABB. 2016. “ABB Velocity Suite.” http://new.abb.com/enterprise-software/energy-portfoliomanagement/market-intelligence-services/velocity-suite. Accessed April 2016.

Barbose, G. 2016. “U.S. Renewables Portfolio Standards: 2016 Annual Status Report.” LBNL1005057. Berkeley, CA: Lawrence Berkeley National

Laboratory. https://emp.lbl.gov/sites/all/files/lbnl-1005057.pdf.

Beamon, A., and M. Leff. 2013. "EOP III Task 1606, Subtask 3-Review of Power Plant Cost and Performance Assumptions for NEMS: Technology Documentation Report. Appendix B of Updated Capital Cost Estimates for Utility Scale Electricity Generating Plants.” Work performed by SAIC Energy, Environment \& Infrastructure, McLean, VA. Washington, D.C.: U.S. Energy Information Administration, April 2013. Accessed Dec. 26, 2014: http://www.eia.gov/

BLM (Bureau of Land Management). 2012. "Approved Resource Management Plan Amendments/ Record of Decision (ROD) for Solar Energy Development in Six Southwestern States." http://blmsolar.anl.gov/documents/docs/peis/Solar_PEIS_ROD.pdf

BNEF (Bloomberg New Energy Finance). 2016a. "First Solar Could Gain Most from Nevada's New Rooftop Fees.” https://www.bnef.com/core/news/108708?e=News\%20Watch

_. 2016b. "H1 2016 US PV Market Outlook."

Bolinger, Mark. 2014. "An Analysis of the Costs, Benefits, and Implications of Different Approaches to Capturing the Value of Renewable Energy Tax Incentives." LBNL-6610E. Berkeley, CA: Lawrence Berkeley National Laboratory.

Brinkman, G., J. Jorgenson, A. Ehlen, and J. H. Caldwell. 2016. "Low Carbon Grid Study: Analysis of a 50\% Emission Reduction in California." NREL/TP-6A20-64884-01. Golden, CO: National Renewable Energy Laboratory.

Cole, W., H. Lewis, B. Sigrin, and R. Margolis. 2016a. "Interactions of rooftop PV deployment with the capacity expansion of the bulk power system." Applied Energy 168 (April 2016): 473481.

Cole, W., T. Mai, J. Logan, D. Steinberg, J. McCall, J. Richards, B. Sigrin, and G. Porro. 2016 b. "2016 Standard Scenarios Report: A U.S. Electricity Sector Outlook." NREL/TP-6A20-66939. Golden, CO: National Renewable Energy Laboratory.

Cole, W., K. Medlock, and A. Jani. 2016c. "A view to the future of natural gas and electricity: An integrated modeling approach." Energy

Economics, http://dx.doi.org/10.1016/j.eneco.2016.03.005

Denholm, P., E. Drury, and R. Margolis. 2009. "The Solar Deployment System (SolarDS) Model: Documentation and Sample Results.” NREL/TP-6A20-45832. Golden, CO: National Renewable Energy Laboratory. 
DOE (U.S. Department of Energy). 2015. "Wind Vision: A New Era for Wind Power in the United States.” DOE/GO-102015-4557. Washington, D.C.: U.S. Department of Energy.

—. 2012. SunShot Vision Study. DOE/GO-102012-3037. Washington, D.C.: U.S. Department of Energy.

Drury, E., P. Denholm, and R. Margolis. 2013. "Sensitivity of Rooftop PV Projections in the SunShot Vision Study to Market Assumptions." NREL/TP-6A20-54620. Golden, CO: National Renewable Energy Laboratory.

EIA. 2016. “Annual Energy Outlook 2016.” DOE/EIA-0383(2016). Washington, D.C.: U.S. DOE Energy Information Administration.

Eurek, K., W. Cole, D. Bielen, N. Blair, S. Cohen, B. Frew, J. Ho, V. Krishnan, T. Mai, and D. Steinberg. 2016. "Regional Energy Deployment System (ReEDS) Model Documentation:

Version 2016.” NREL/TP-6A20-67067. Golden, CO: National Renewable Energy Laboratory.

Gagnon, P., B. Sigrin, and M. Gleason. 2016. "The Impacts of Changes to Nevada's Net Metering Policy on the Economics and Adoption of Distributed Photovoltaics." NREL/TP6A20-65298. Golden, CO: National Renewable Energy Laboratory.

GTM (Greentech Media Research) and SEIA (Solar Energy Industries Association). 2016a. “U.S. Solar Market Insight Report 2016 Q1.” Solar Energy Industries Association, SEIA.

—. 2016b. “U.S. Solar Market Insight Report 2016 Q2.” Solar Energy Industries Association, SEIA.

Heeter, J., P. Beiter, F. Flores-Espino, D. Hurlbut, and C. Liu. 2015. "Quantifying the Level of Cross-State Renewable Energy Transactions.” Clean Energy States Alliance webinar. NREL/PR6A20-63458. Golden, CO: National Renewable Energy

Laboratory. http://www.nrel.gov/docs/fy15osti/63458.pdf.

Holt, E. 2014. "Potential RPS Markets for Renewable Energy Generators." Prepared for the State-Federal RPS Collaborative by Ed Holt \& Associates, Inc. Montpelier, VT: Clean Energy States Alliance. http://www.cesa.org/assets/2014-Files/Potential-RPS-Markets-Report-HoltJanuary-2014.pdf.

Mai, T., W. Cole, V. Krishnan, and M. Bolinger. 2015. "Impact of Federal Tax Policy on UtilityScale Solar Deployment Given Financing Interactions." Presentation by the National Renewable Energy Laboratory. Golden, CO: National Renewable Energy Laboratory. NREL/PR-6A2065014.

Mai, T., W. Cole, E. Lantz, C. Marcy, and B. Sigrin. 2016. "Impacts of Federal Tax Credit Extensions on Renewable Deployment and Power Sector Emissions.” NREL/TP-6A20- 65571. Golden, CO: National Renewable Energy Laboratory. http://www.nrel.gov/docs/fy16osti/65571.pdf. 
Mai, T., R. Wiser, D. Sandor, G. Brinkman, G. Heath, P. Denholm, D.J. Hostick, N. Darghouth, A. Schlosser, and K. Strzepek. 2012. "Exploration of High-Penetration Renewable Electricity Futures." Vol. 1 of Renewable Electricity Futures Study. NREL/TP-6A20-52409-1. Golden, CO: National Renewable Energy Laboratory.

NERC (North American Electric Reliability Corporation). 2015. "2015 Summer Reliability Assessment." Atlanta,

GA. http://www.nerc.com/pa/RAPA/ra/Reliability\%20Assessments\%20DL/2015 Summer_Reli ability_Assessment.pdf.

Nevada Power Company, 2016. "Schedule NMR-A RESIDENTIAL AND SMALL GENERAL SERVICE-TIME-OF-USE-NET METERING." PUCN Sheet No. 33E, 7th Revision. Nevada Power Company d/b/a NV

Energy. https://www.nvenergy.com/company/rates/snv/schedules/images/NMR A South.pdf.

NREL (National Renewable Energy Laboratory). 2016. Annual Technology Baseline (ATB). http://www.nrel.gov/analysis/data tech_baseline.html.

Ong, S., C. Campbell, P. Denholm, R. Margolis, and G. Heath. 2013. "Land-Use Requirements for Solar Power Plants in the United States.” NREL TP-6A20-56290. Golden, CO: National Renewable Energy Laboratory.

Short, W., P. Sullivan, T. Mai, M. Mowers, C. Uriarte, N. Blair, D. Heimiller, and A. Martinez. 2011. "Regional Energy Deployment System (ReEDS)." NREL/TP-6A20-46534. Golden, CO: National Renewable Energy Laboratory.

Steinberg, D., D. Bielen, and K. Eurek. (forthcoming). "Examining the National and Regional Impacts of the Clean Power Plan on the Power Sector." Golden, CO: National Renewable Energy Laboratory.

Sigrin, B., M. Gleason, R. Preus, I. Baring-Gould, and R. Margolis. 2016. "The Distributed Generation Market Demand Model (dGen): Documentation.” NREL TP-6A20-65231. Golden, CO: National Renewable Energy Laboratory.

Sullivan, P., W. Cole, N. Blair, E. Lantz, V. Krishnan, T. Mai, D. Mulcahy, and G. Porro. 2015. "2015 Standard Scenarios Annual Report: U.S. Electric Sector Scenario Exploration." NREL/TP-6A20-64072. Golden, CO: National Renewable Energy Laboratory.

WECC (Western Electricity Coordinating Council). 2015. 2024 Common Case version 1.5. https://www.wecc.biz/Reliability/2024-Common-Case.zip.

White, E., K. Hlava, J. Kuiper, B. Moore, K. Rollins, K. Wescott, and E. Zvolanek. 2016. "Section 368 Corridor Study." ANL/EVS-15/6. Argonne, IL: Argonne National Laboratory.

Wiser Capital. 2016. "Green is the New Black: Solar Investment Gaining Momentum.” http://d3s3a1epzxq0r3.cloudfront.net/img/MiniReportJune2015 updated.pdf. 


\section{Appendix A. Regional Dynamics}

ReEDS models state Renewable Portfolio Standards (RPS), including technology set-asides, and Renewable Energy Credits (RECs) that can count toward RPS compliance. RPS rules are complex and can vary significantly between states. Our RPS representation in ReEDS attempts to model the primary impacts of these RPS rules but includes many simplifying assumptions. Table A1 summarizes the RPS targets, technology set-asides, and REC trading within ReEDS.

The left side of Table A1, which can be found at the end of this appendix, shows the respective RPS targets and technology set-asides for years 2020, 2025 and 2030 as a percentage of state electricity sales as modeled within ReEDS. These values - along with many other data that we use to represent nuanced RPS rules - are based on data compiled by Lawrence Berkeley National Laboratory (LBNL), which takes into account the in-state REC multiplier incentives and load adjustments (i.e., sales weighted RPS targets considering different load serving entities, such as investor owned utilities, municipal utility, co-operatives, etc.). ${ }^{27}$ Solar includes UPV and rooftop PV, wind includes both land-based and offshore technologies, and DG includes rooftop PV and ground-mounted PV systems located within the distribution network. ${ }^{28}$ ReEDS also models alternate compliance payments (ACP) for unmet RPS requirement for both main RPS targets and solar set-asides as is consistent with the available data.

Technology eligibility for state RPS requirements is appropriately modeled for each state. For instance, California's RPS does not allow in-state rooftop solar technologies to contribute towards its RPS. Additionally, every state has specific rules regarding hydropower generation's eligibility towards contributing RECs, which are usually based on each unit's vintage and size (e.g., small hydro with specific capacity cut-offs are eligible in some states). ReEDS models these in terms of allowable capacity fractions (estimated from ABB Velocity Suite database (ABB 2016)), which is imposed on each state's total hydro generation thereby limiting the amount of hydropower RECs that each state could generate. Additionally, ReEDS also imposes an upper limit on the total hydropower RECs that a state can use towards its RPS based on historical data as compiled and estimated by LBNL.

We also model restricted eligibility of existing renewable capacity to contribute to future RPS targets. In other words, while the amount of renewable generation in 2014 exceeds RPS requirements in that year, some of this renewable generation has contractual or other obligations that prevent it from being eligible to meet RPS requirements. This eligibility restriction, estimated by region and technology type, was estimated by LBNL. For the continental United States, we estimate that $25 \%$ of renewable generation in excess of RPS demand in 2014 is eligible to meet RPS demand after 2014. We do not model banking or borrowing of RECs.

The right side of Table A1 lists the allowable states from which each state may import RECs; inter-state REC transactions that are required to be bundled with energy are marked with an asterisk. With the exception of California, ReEDS enforces an upper limit on the total RECs (including both bundled and unbundled) that can be imported for that state's RPS compliance.

\footnotetext{
${ }^{27}$ See Barbose (2016) and https://emp.lbl.gov/projects/renewables-portfolio

${ }^{28}$ See Database of State Incentives for Renewables \& Efficiency (DSIRE ) website: http://www.dsireusa.org/. If data is unavailable, ReEDS forces RPS target to be met by using a default ACP and SACP of \$200/MWh and $\$ 400 / \mathrm{MWh}$ respectively.
} 
For California alone, due to its unique out-of-state rules, ReEDS enforces two upper limits, one on the total unbundled REC imports and the other on the total bundled REC imports. There are a myriad of possibilities of inter-state REC transactions, both in terms of which two states can transact and in terms of the quantity of those transactions. To constrain the solution space of ReEDS to credible values, the inter-state REC trading modeling are based on historical observations (Holt 2014), as shown in the final two columns of Table A1. The out-of-state total REC import percentages for each state in Table A1 are limited to those observed in 2012-2013 (Heeter et al. 2015).

The treatment of inter-state REC trading for California is complicated because it has different rules for bundled and unbundled RECs. While some states have a limit on the total amount of out-of-state RECs that may be imported (i.e., a combined limit on bundled and unbundled RECs), the RPS program in California imposes separate limits on the amount of bundled and unbundled RECs that can be imported. As a result, we include separate representations for bundled and unbundled RECs for California in ReEDS. California has no explicit limit on bundled RECs, but it may only meet up to $25 \%$ of its RPS target by importing unbundled RECs. After 2013, this restriction on unbundled REC imports reduced to 15\%, and from 2017 it goes down to $10 \%$, per California's RPS Bucket 3 rule. ${ }^{29}$

Our No CA REC Limits scenario is motivated by uncertainties in California's future REC trading rules. In particular, the proximity of and transmission connections from certain model regions in the U.S. West to California raise the possibility that new renewable generation in this region can contribute more to California's RPS requirement than reflected in our default RPS representation. In this No CA REC Limits scenario, we allow 100\% of out-of-state unbundled resources to contribute to California's RPS target instead of the default unbundled REC import limit. In combination with the default unlimited out-of-state bundled REC allowance, this results in unlimited out-of-state total RECs imports to contribute to California's RPS requirement, limited only by the resource availability in those exporting states and transmission line limits for bundled RECs.

More widely across the U.S. West, the treatment of REC trading in ReEDS is reflective of broader regional dynamics, including the proposed expansion of the CAISO regional energy market $^{30}$ and the recent and ongoing expansion of the CAISO western EIM. ${ }^{31}$ These aggregations could allow for greater market efficiencies and renewable resource sharing across the region, with notable implications on the use of out-of-state resources for compliance with California's RPS goals. Particularly relevant to this analysis, the possibility of greater cooperation or participation of NV Energy in the CAISO market may alter how renewable generation in Nevada is accounted for in California RPS requirements. Our No CA REC Limits

\footnotetext{
${ }^{29}$ See information on California's RPS: http://www.dra.ca.gov/general.aspx?id=2160.

${ }^{30}$ The proposed merging of PacifiCorp, and potentially other regions in the western United States, into CAISO's regional energy market is currently under evaluation:

http://www.caiso.com/informed/Pages/RegionalEnergyMarket/BenefitsofaRegionalEnergyMarket.aspx

${ }^{31}$ The EIM is a real-time, security-constrained economic dispatch on imbalances, running every five minutes. It therefore does not include the other aspects of the large ISO markets and is an approach to pooling the economic dispatch of imbalances. Current participants include CAISO and PacifiCorp. NV Energy, Puget Sound Energy, and Arizona Public Service utilities are planned to join in 2016, and Portland General Electric is planned to join in 2017. Each additional EIM member increases the effective balancing size of this market. See CAISO's website for more details: http://www.caiso.com/informed/pages/stakeholderprocesses/energyimbalancemarket.aspx
} 
scenario is designed to address the possibility that these resources would effectively count unbundled out-of-state resources. While our default representation of the California RPS and the representation in the No CA REC Limits scenario span a range of possibilities, we acknowledge that other California RPS compliance scenarios outside of that range may also be possible.

Table A1. State RPS Targets and Technology Set-Asides in ReEDS

\begin{tabular}{|c|c|c|c|c|c|}
\hline \multirow[b]{2}{*}{ State } & \multicolumn{3}{|c|}{ RPS target / Solar / DG / Wind set-asides (\%) } & \multirow{2}{*}{$\begin{array}{l}\text { Allowable states } \\
\text { for REC import, } \\
\text { includes Canadian } \\
\text { provinces } \\
\text { (*bundling } \\
\text { requirement) }\end{array}$} & \multirow{2}{*}{$\begin{array}{l}\text { REC } \\
\text { import } \\
\text { limit ( } \% \text { of } \\
\text { RPS } \\
\text { target) }\end{array}$} \\
\hline & 2020 & 2025 & 2030 & & \\
\hline$A Z$ & $5.8 /-/ 1.7 /-$ & 8.7/-/2.6/- & 8.7/-/2.6/- & $\mathrm{CA}^{*}, \mathrm{CO}^{*}, \mathrm{NM}^{*}$ & 100 \\
\hline CA & $32.2 /-/-/-$ & $39 /-/-/-$ & $48.8 /-/-/-$ & $\begin{array}{l}\mathrm{AZ}^{*}, \mathrm{ID}, \mathrm{MT}, \mathrm{NM}, \\
\mathrm{NV}^{*}, \mathrm{OR}^{*}, \mathrm{UT}^{*}, \mathrm{WA}, \\
\mathrm{WY}^{*}, \mathrm{MEX}^{*}\end{array}$ & $\begin{array}{l}25<2013 \\
15<2016 \\
10>2017 \\
\text { (only } \\
\text { unbundled, } \\
100 \% \text { for } \\
\text { bundled) }\end{array}$ \\
\hline $\mathrm{CO}^{\mathrm{a}}$ & $19.1 /-/ 0.8 /-$ & 19.5/-/0.8/- & 19.8/-/0.8/- & WY & 8 \\
\hline CT & 23/-/-/- & 23/-/-/- & 23/-/-/- & $\begin{array}{l}\mathrm{MA}, \mathrm{ME}, \mathrm{NH}, \mathrm{NY}^{*} \\
\mathrm{RI}, \mathrm{VT}, \mathrm{NB}^{*}, \mathrm{NL}^{*} \\
\mathrm{NS}^{*}, \mathrm{QC}^{*}, \mathrm{NFI}^{*} \\
\mathrm{PEI}^{*}\end{array}$ & 59 \\
\hline $\mathrm{DE}^{\mathrm{b}}$ & 14.3/1.9/-/- & 18.9/3/-/- & 19/3/-/- & $\begin{array}{l}\mathrm{IL}^{*}, \mathrm{IN}^{*}, \mathrm{MD}, \mathrm{PA}^{*} \\
\mathrm{VA}^{*}, \mathrm{WV}^{*}\end{array}$ & 94 \\
\hline$I^{b, c}$ & $8 / 0.1 / 0.1 / 3.5$ & $11.9 / 0.2 / 0.1 / 5.2$ & $12.2 / 0.21 / 0.1 / 5.4$ & $\begin{array}{l}\text { IA, IN, MD, MN, MO, } \\
\text { ND, NY, OH, PA, } \\
\text { SD, VA, WI, WV }\end{array}$ & 60 \\
\hline$M A^{b}$ & $14.8 / 3.5 /-/-$ & 19.1/3.6/-/- & 23.4/3.6/-/- & 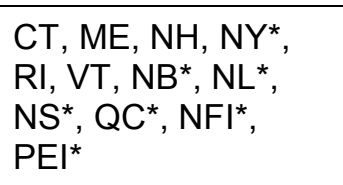 & 62 \\
\hline$M D^{b, d}$ & 18.1/1.9/-/- & 20.6/2.1/-/- & 23.1/2.4/-/- & $\begin{array}{l}\mathrm{DE}, \mathrm{IA}, \mathrm{IL}^{*}, \mathrm{IN}^{*}, \\
\mathrm{NC}^{*}, \mathrm{NY}^{*}, \mathrm{OH}^{*}, \mathrm{PA}^{*}, \\
\mathrm{TN}^{*}, \mathrm{VA}^{*}, \mathrm{WI}, \mathrm{WV}^{*}\end{array}$ & 70 \\
\hline ME & $34.1 /-/-/-$ & $34.1 /-/-/-$ & $34 /-/-/-$ & $\begin{array}{l}\mathrm{CT}, \mathrm{MA}, \mathrm{NH}, \mathrm{RI}, \mathrm{VT}, \\
\mathrm{NB}^{*}, \mathrm{NL}^{*}, \mathrm{NS}^{*}, \mathrm{QC}^{*} \\
\mathrm{NFI}^{*}, \mathrm{PEI}^{*}\end{array}$ & 18 \\
\hline MI & 8.6/-/-/- & $8.4 /-/-/-$ & 8.3/-/-/- & IA, IN, MN, WI & 0 \\
\hline MN & 25.3/0.8/0.1/11.2 & 28.1/0.8/0.1/11.2 & $28.1 / 0.8 / 0.1 / 11.2$ & $\begin{array}{l}\text { IA, MI, ND, SD, WI, } \\
\text { MB, ON, SK }\end{array}$ & 24 \\
\hline $\mathrm{MO}^{\mathrm{b}}$ & 6.8/0.1/-/- & $10.1 / 0.2 /-/-$ & $10.1 / 0.2 /-/-$ & $\mathrm{IA}, \mathrm{KS}$, & 94 \\
\hline
\end{tabular}




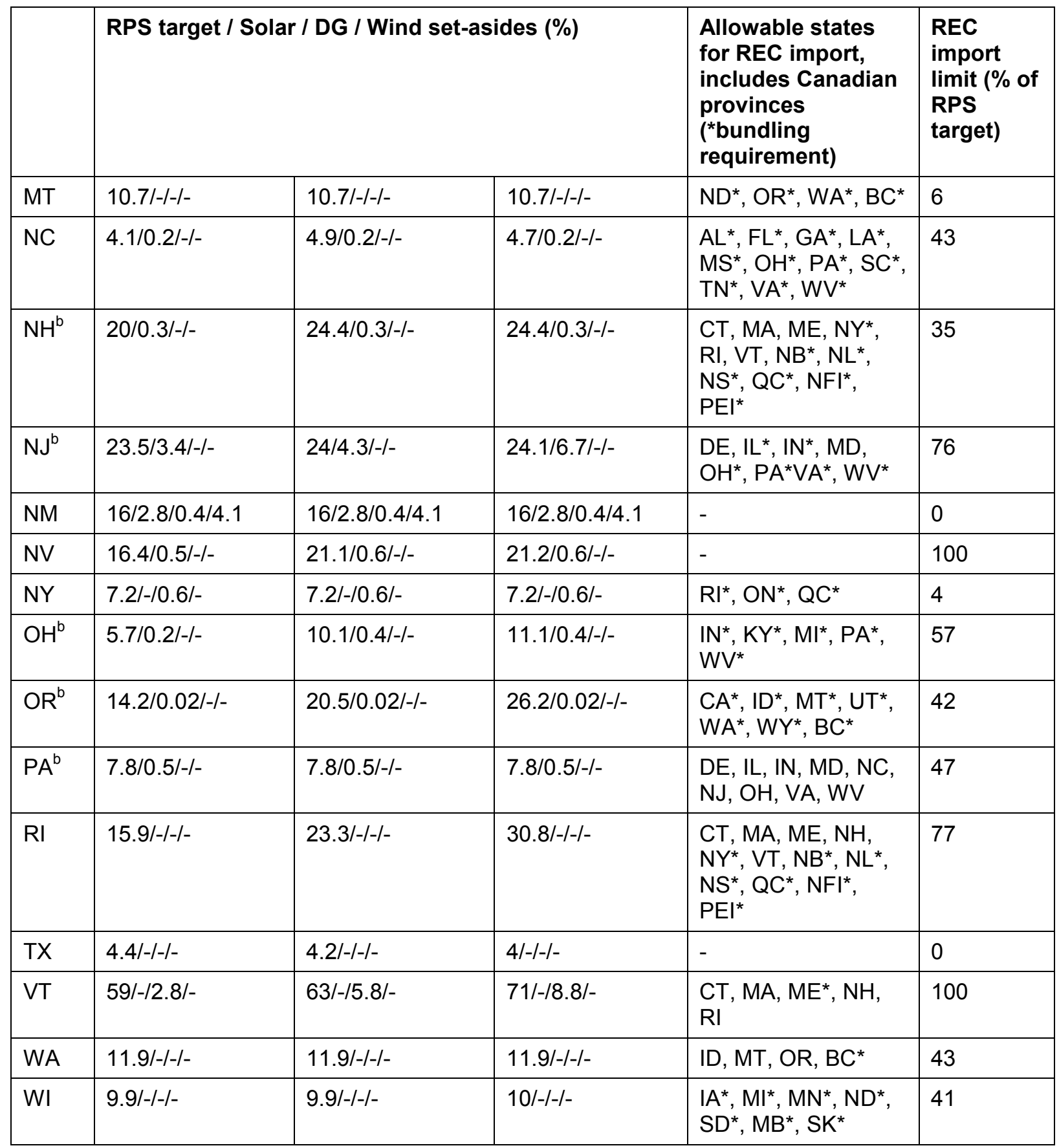

${ }^{a}$ Based on historical observation, only $50 \%$ of actual DG carve out for CO assumed to be met using distributed solar technologies (DUPV and distPV)

${ }^{b}$ Based on historical observation, the solar carve out in these states are seen to be met only using distribution side solar technologies. Hence the solar carve out in these states are modeled as DG carve out in ReEDS.

${ }^{c}$ Illinois allows for $50 \%$ of its RPS target to be met using ACP, and hence ReEDS targets are adjusted to reflect this.

${ }^{\mathrm{d}}$ Washington DC RPS targets are rolled into MD (Washington DC load also rolled into MD) 


\section{Appendix B. Data for Figure 4 and Figure 6}

The data corresponding to Figure 4 and Figure 6 are tabulated in Table B1 and B2 respectively.

Table B1. U.S. West 2014-2030 Cumulative Capacity

Utility PV and Rooftop PV are on a DC-basis; all others are on an AC-basis.

\begin{tabular}{c|ccccccccccc}
\hline GW & CSP & Rooftop PV & UPV & Wind & Hydro & Geo & Nuclear & Coal & NGas & Storage & Other \\
\hline 2014 & 1.71 & 4.56 & 7.23 & 18.90 & 48.27 & 2.69 & 7.37 & 31.26 & 69.15 & 4.90 & 16.17 \\
\hline 2016 & 1.82 & 7.71 & 11.31 & 20.02 & 48.83 & 2.88 & 7.37 & 30.81 & 70.86 & 4.90 & 15.42 \\
2018 & 1.83 & 10.41 & 11.31 & 24.62 & 49.73 & 2.92 & 7.37 & 29.52 & 70.84 & 4.90 & 11.38 \\
\hline 2020 & 1.83 & 14.28 & 11.31 & 31.94 & 50.03 & 3.82 & 7.37 & 27.52 & 70.75 & 4.90 & 8.52 \\
\hline 2022 & 1.83 & 17.10 & 11.31 & 31.89 & 50.14 & 3.82 & 7.37 & 26.34 & 70.75 & 4.90 & 7.37 \\
\hline 2024 & 1.83 & 19.65 & 17.58 & 31.65 & 50.82 & 4.06 & 7.37 & 25.92 & 70.75 & 4.90 & 6.10 \\
\hline 2026 & 1.83 & 22.54 & 20.92 & 31.08 & 51.16 & 4.55 & 7.37 & 24.94 & 76.39 & 4.93 & 3.35 \\
\hline 2028 & 1.83 & 25.46 & 29.63 & 30.77 & 51.23 & 4.55 & 7.37 & 23.75 & 81.12 & 4.99 & 1.90 \\
\hline 2030 & 2.10 & 28.39 & 33.06 & 30.77 & 51.26 & 5.40 & 7.37 & 23.16 & 83.56 & 5.05 & 1.79 \\
\hline
\end{tabular}

Table B2. U.S. West 2014-2030 Generation

\begin{tabular}{l|llllllllllllll}
\hline TWh $_{\text {AC }}$ & CSP & $\begin{array}{c}\text { Rooftop } \\
\text { PV }\end{array}$ & UPV & Wind & Hydro & Geo Nuclear & Coal & Ngas & \multicolumn{4}{c}{$\begin{array}{c}\text { Canada } \\
\text { Imports }\end{array}$} & Other Storage & $\begin{array}{c}\text { Trans- } \\
\text { mission }\end{array}$ \\
\hline 2014 & 4.71 & 7.92 & 17.37 & 50.52 & 165.02 & 20.05 & 58.29 & 200.43 & 199.12 & -2.79 & 8.27 & 0.00 & -7.31 \\
\hline 2016 & 5.13 & 13.38 & 27.19 & 54.80 & 180.23 & 21.43 & 58.29 & 176.43 & 183.93 & 0.21 & 8.06 & 0.00 & -3.68 \\
\hline 2018 & 5.13 & 18.07 & 26.92 & 75.63 & 183.87 & 21.73 & 58.29 & 188.03 & 159.61 & 0.24 & 8.28 & -0.01 & -5.65 \\
\hline 2020 & 5.13 & 24.79 & 26.64 & 108.18 & 184.91 & 28.43 & 58.29 & 168.04 & 156.34 & -1.16 & 8.28 & -0.04 & -6.47 \\
\hline 2022 & 5.13 & 29.51 & 26.34 & 107.08 & 185.30 & 28.43 & 58.29 & 173.16 & 164.29 & -1.60 & 8.28 & -0.16 & -7.01 \\
\hline 2024 & 5.13 & 33.71 & 41.57 & 106.87 & 187.63 & 30.24 & 58.29 & 164.86 & 170.01 & 1.06 & 8.27 & -0.27 & -5.72 \\
\hline 2026 & 5.13 & 38.35 & 48.95 & 105.53 & 188.95 & 33.88 & 58.29 & 155.03 & 179.81 & 0.91 & 8.27 & -0.36 & -5.39 \\
\hline 2028 & 5.13 & 42.95 & 68.01 & 106.12 & 189.16 & 33.88 & 58.29 & 134.91 & 191.19 & 0.27 & 8.27 & -0.61 & -4.57 \\
\hline 2030 & 6.58 & 47.33 & 74.63 & 108.61 & 189.26 & 40.21 & 58.29 & 118.88 & 195.95 & 0.45 & 8.27 & -0.99 & -4.15 \\
\hline
\end{tabular}




\section{Appendix C. State-level UPV Deployment Projections}

The main body of this report presented an analysis of the trends in utility-scale PV (UPV) deployment and generation in the U.S. West, with state-level results for Nevada, California, and Arizona. Section 3.3.4 of the main text then placed our ReEDS total PV (rooftop PV and UPV) cumulative capacity estimates for the U.S. West in the context of other published projections. In this appendix section, we provide similar comparisons, but focused here on state-level projections for total PV and UPV.

California, Arizona, and Nevada capacity projections are compared with the ReEDS scenarios for total PV in Figure $\mathrm{C} 1$ and UPV in Figure C2 for those sources from Table 5 providing statelevel and technology-specific estimates. The ReEDS Central scenario is shown as a single line, and the full range of deployment across all other ReEDS scenarios is captured in the shaded area. As discussed in Section 3.3.4, the ReEDS projections capture a wide range of deployment possibilities. However, some sources estimate larger and/or more rapid deployment than even our most-favorable ReEDS scenarios, especially in California and Nevada in 2020. 

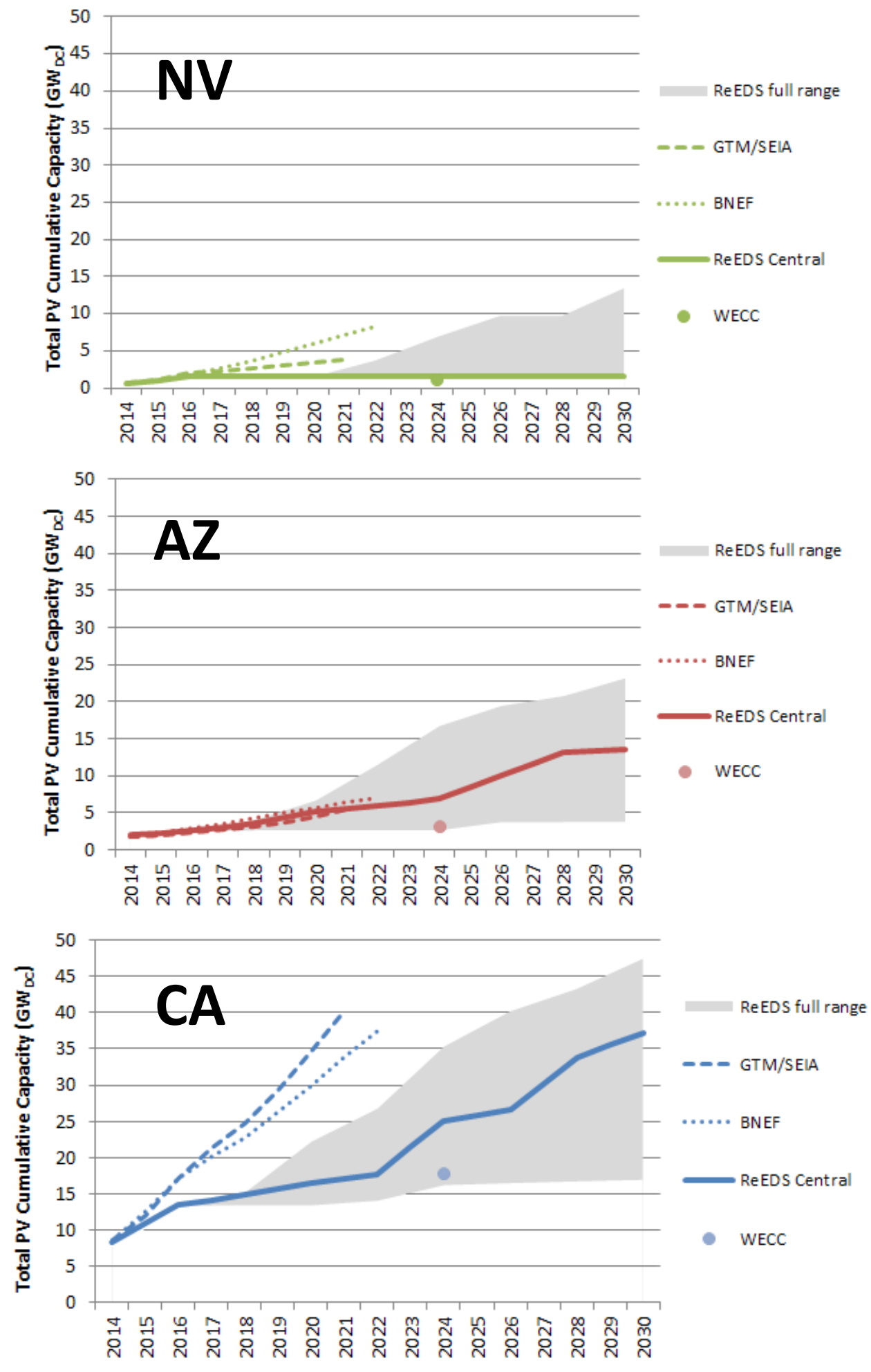

Figure $\mathrm{C} 1$. State-level total PV cumulative capacity 

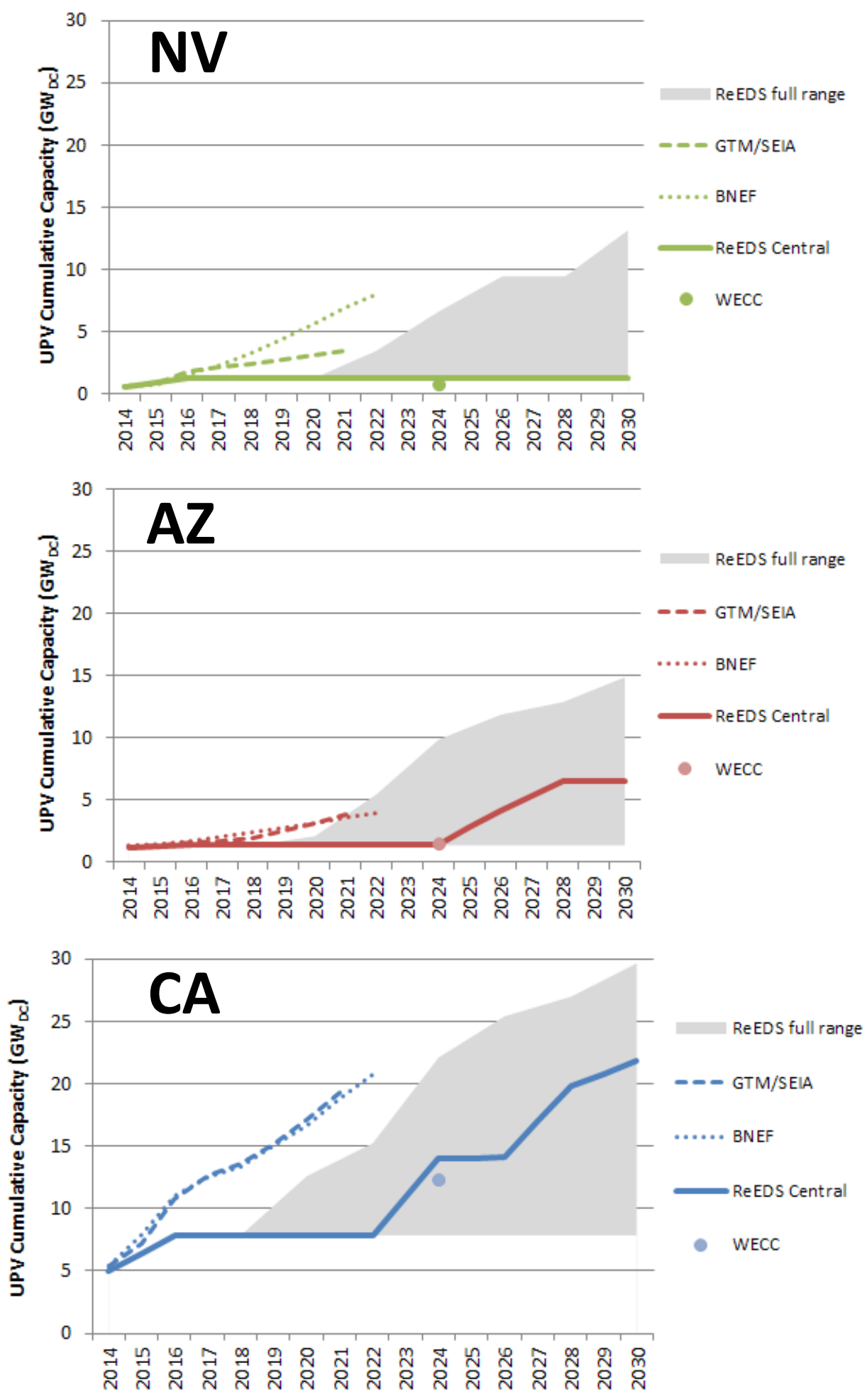

Figure C2. State-level UPV cumulative capacity 